\title{
Inhibitive effect of Pt on Pd-hydride formation of Pd@Pt core-shell electrocatalysts: An in situ EXAFS and XRD study
}

\author{
Anna M. Wise ${ }^{\mathrm{a}, \mathrm{b}}$, Peter W. Richardson ${ }^{\mathrm{a}}$, Stephen W.T. Price ${ }^{\mathrm{a}, \mathrm{c}}$, Gaël Chouchelamane ${ }^{\mathrm{a}}$, Laura Calvillo \\ ${ }^{\text {a }}$, Patrick J. Hendra ${ }^{\text {a, d }}$, Michael F. Toney ${ }^{\text {b }}$, Andrea E. Russell ${ }^{\text {a, }}{ }^{*}$ \\ ${ }^{a}$ Chemistry, University of Southampton, Highfield, Southampton SO17 1BJ, UK \\ b Stanford Synchrotron Radiation Lightsource, SLAC National Accelerator Laboratory, Menlo Park, CA 94025, United States \\ ${ }^{c}$ Diamond Light Source Ltd., Harwell Science and Innovation Campus, Fermi Ave, Didcot, Oxfordshire OX11 0QX, UK \\ ${ }^{\mathrm{d}}$ Ventacon UK, Gable Cottage, Crawley, Hampshire SO21 2PR, UK
}

\section{A R T I C L E I N F O}

Article history:

Received 19 March 2017

Received in revised form

30 November 2017

Accepted 26 December 2017

Available online 27 December 2017

Keywords:

Electrocatalyst

EXAFS

XRD

Core-shell

\section{A B S T R A C T}

In situ EXAFS and XRD have been used to study the electrochemical formation of hydride phases, $\mathrm{H}_{\mathrm{abs}}$, in $0.5 \mathrm{M} \mathrm{H}_{2} \mathrm{SO}_{4}$ for a Pd/C catalyst and a series of Pd@Pt core-shell catalysts with varying Pt shell thickness, from 0.5 to 4 monolayers. Based on the XRD data a 3\% lattice expansion is observed for the Pd/C core catalyst upon hydride formation at $0.0 \mathrm{~V}$. In contrast, the expansion was $\leq 0.6 \%$ for all of the core-shell catalysts. The limited extent of the lattice expansion observed suggests that hydride formation, which may occur during periodic active surface area measurements conducting during accelerated aging tests or driven by $\mathrm{H}_{2}$ crossover in PEM fuel cells, is unlikely to contribute significantly to the degradation of Pd@Pt core-shell electrocatalysts in contrast to the effects of oxide formation.

\section{Introduction}

The slow kinetics of the oxygen reduction reaction (ORR) represent a major challenge in the commercialisation of proton exchange membrane (PEM) fuel cells. Pt nanoparticles supported on carbon are commonly used as ORR electrocatalysts, however, the high cost of Pt is another cause for concern in terms of the commercial viability of these systems. Thus, strategies for reducing the Pt loading and/or improving the activity of the catalysts for ORR have been the subject of significant research [1]. One such strategy has been the development of core-shell nanoparticle catalysts (often noted as core@shell in the literature), whereby a less expensive metal is used as the core, with the expensive Pt atoms confined to a thin shell at the surface of the catalyst nanoparticles [2-5]. This atom efficiency can offer significant enhancements in the mass activity, per Pt atom, of the resulting catalyst. Where there is a synergistic effect of the core on the shell, the core-shell structure may even offer greater enhancements, as illustrated by the correlation between the measured ORR activity and calculated d-

\footnotetext{
* Corresponding author.

E-mail address: a.e.russell@soton.ac.uk (A.E. Russell).
}

band centre for monolayers of Pt deposited on to the (111) faces of a variety of metals [6]. In that study, Zhang et al. found the maximum specific activity (current per $\mathrm{cm}^{2} \mathrm{Pt}$ ) for the Pt monolayer deposited on a Pd (111) surface. Adzic's group then went on to show that the enhanced ORR activity could be reproduced for carbon supported nanoparticle Pd@Pt electrocatalysts [7-10]. Subsequently, such Pd@Pt core-shell catalysts have received considerable further attention as illustrated by two comprehensive reviews [11,12].

The hydrogen storage properties of Pd@Pt core-shell catalyst nanoparticles are also of interest [13-15]. Whilst storage of hydrogen within a metal lattice does not, itself, offer a viable solution for applications such as storage of hydrogen fuel for fuel cells in automobiles owing to their weight, metal catalyst nanoparticles can facilitate hydrogen storage in other materials by spillover [16], whereby the adsorption of hydrogen is initiated at the surface of the metal nanoparticles [17]. Both the nanoparticle size and Pt shell thickness have been shown to have an effect on the hydrogen storage of the materials [18].

The uptake of hydrogen within the lattice of the Pd core may have an effect on the durability of Pd@Pt core-shell catalysts, even when used as cathodes in PEM fuel cells, as a considerable expansion of the lattice accompanies hydride formation for carbon supported Pd nanoparticles [19]. The active area of the 
electrocatalyst is often determined via measurement of hydrogen upd during accelerated aging or stress tests $[20,21]$ and this requires potential cycling to potentials at which hydride formation may occur. Additionally, hydrogen from the anode is able to crossover through the membrane from the anode side, reaching the cathode catalyst. Such crossover is evident in the accelerated aging study of a Pd@Pt cathode electrocatalyst reported by Ball et al. [22] They observed the formation of a band of metal (Pt and Pd) at the cathode/membrane interface due to dissolution of Pt and Pd from the cathode and subsequent reduction by the hydrogen gas. Such crossover may be further exacerbated during start-up of a PEM fuel cell, when the anode side is flushed with hydrogen prior to operation to avoid conditions of fuel starvation, when the cathode catalyst may be exposed an atmosphere of hydrogen.

In the investigation reported here Pd@Pt core-shell electrocatalysts, with Pt shells corresponding to $0.5,1$, and 4 monolayers are explored to show the effects of increasing shell thickness. We have previously reported the relative oxygen reduction activity of the various catalysts studied in this report [23], with the maximum mass activity, measured in terms of both $\mathrm{A} \mathrm{mg} \mathrm{Pt}_{\mathrm{Pt}}^{-1}$ and $\mathrm{A} \mathrm{mg} \mathrm{Pt}_{\mathrm{Pt}}^{-1} \mathrm{Pd}$, being found for a catalyst with a shell thickness of 1.5 monolayers. In the study presented herein, the electrochemical formation of a hydride phase has been monitored in situ using both X-ray diffraction (XRD) and extended X-ray absorption fine structure (EXAFS) to observe the accompanying lattice expansion and its effects on the inter-atomic distances of each of the metalneighbour pairs, respectively.

\section{Experimental}

\subsection{Catalyst preparation and characterisation}

The carbon supported Pd core - Pt shell (Pd@Pt) catalysts with Pt shell thicknesses of $0.5,1$, and 4 monolayers were prepared via controlled surface reaction as reported in detail previously [24-27]. In brief, the $20 \mathrm{wt} \% \mathrm{Pd} / \mathrm{C}$ core catalyst was prepared from Pd nitrate precipitated onto a slurry of the carbon support by addition of $1 \mathrm{~mol} \mathrm{dm}^{-3} \mathrm{NaOH}$. The dried core catalyst was reduced under $\mathrm{H}_{2}(\mathrm{~g})$ and the appropriate volume of the Pt precursor solution was added to provide the desired number of monolayers of Pt as determined from prior measurement of the surface area of the Pd core catalyst based on $\mathrm{CO}$ chemisorption measurements. The 0.5 and 1 monolayer catalysts were prepared using a single modification step, whilst the 4 monolayer catalyst was prepared by sequential depositions of 2 monolayers of Pt. A bimetallic alloy catalyst PtPd/C was prepared by further heating of a Pd@Pt $2 \mathrm{ML}$ catalyst in $5 \% \mathrm{H}_{2}$ in $\mathrm{N}_{2}$. Caution the reduced catalysts, formed by exposure to $\mathrm{H}_{2}$ or an $\mathrm{H}_{2} /$ $\mathrm{N}_{2}$ mixture are highly active (will catch fire) in air and require passivation by a gradually increasing the fraction of air in the flowing gas stream. The core catalyst Pd/C and a commercial Pt/C (Johnson Matthey) were also used as electrodes to facilitate comparison.

The compositions of all of the catalysts were confirmed via ICPAES. The average particle size and particle size distribution of the as-prepared materials were measured using TEM by grinding the catalyst samples between two glass slides and dusting on to a holey carbon coated $\mathrm{Cu}$ TEM grid. Measurements were made using a Tecnai F20 TEM microscope with a voltage of $200 \mathrm{kV}$. Powder XRD was carried out using a Bruker AXS D8 diffractometer with a Ni filtered $\mathrm{Cu} \mathrm{K}_{\alpha}$ source. The patterns were analysed via the Rietveld method.

\subsection{Electrodes and electrochemistry}

Catalyst electrodes were prepared by brush-coating a catalystionomer ink onto teflonated carbon paper to give an electrode of the desired Pt loading for the experiment to be carried out (i.e. sufficient metal loading to enable detection in X-ray measurements). It was ensured that the geometrical area was the same for all electrodes by using a circular punch to cut electrodes with an area of $3.14 \mathrm{~cm}^{2}$, and fully immersing the electrodes in the electrolyte during the electrochemical measurements. The ink was prepared by sonication and homogenisation of a mixture of the catalyst powder, aqueous Nafion solution and demineralised water, with the volume of Nafion used calculated to give a loading of $80 \mathrm{wt}$ \% Nafion solids with respect to carbon, and water added as necessary to obtain an ink of a suitable viscosity. Thin layers of ink were painted onto the carbon paper, drying the electrode and rotating it by $90^{\circ}$ between coats to ensure an even distribution of ink on the electrode. Once the desired loading had been reached the electrode was hot-pressed at $180^{\circ} \mathrm{C}$ to bind the ink to the carbon paper. Before electrochemical testing, the electrodes were hydrated by boiling in demineralised water.

The electrochemical characteristics of the catalyst electrodes were assessed by cyclic voltammetry (CV) in $\mathrm{N}_{2}$ purged $1 \mathrm{M} \mathrm{H}_{2} \mathrm{SO}_{4}$ using a sweep rate of $10 \mathrm{mVs}^{-1}$, cycling between $0.02 \mathrm{~V}-1.00 \mathrm{~V}$ vs. RHE (reversible hydrogen electrode). Monolayer CO stripping voltammetry was carried out to determine the ECA (electrochemically active surface area), with $\mathrm{CO}$ being adsorbed by holding the potential at $0.15 \mathrm{~V}$ vs. RHE whilst purging the electrolyte with $\mathrm{CO}$ followed by purging with $\mathrm{N}_{2}$. The three-electrode cell consisted of the working electrode with an Au wire contact, a Pt gauze counter electrode and a mercury mercurous sulphate (MMS) reference electrode ( $0.69 \mathrm{~V}$ vs. RHE). The electrode potential was controlled using an Autolab PGSTAT30 potentiostat.

In situ X-ray measurements were carried out at room temperature using a custom-designed electrochemical cell, the design of which is described in detail, along with technical drawings (Figs. S1 and $\mathrm{S} 2$ ) in the supplementary information. In brief, the working electrode, prepared as detailed above, was held in place using a flattened piece of gold wire, with a Pt wire used as the counter electrode, both of which were kept well clear of the incident X-ray beam. The MMS reference electrode was connected via a short length of tubing connecting the electrolyte. The electrolyte used was $\mathrm{N}_{2}$-purged $0.5 \mathrm{M} \mathrm{H}_{2} \mathrm{SO}_{4}$ and was introduced into the cell via a peristaltic pump. The lower acid concentration was used for the in situ X-ray measurements to satisfy the safety concerns of the beamline staff. The potential was controlled using a $\mu$ Autolab III potentiostat. CVs were collected between $1.00 \mathrm{~V}$ and $0.05 \mathrm{~V}$ vs. RHE at scan rates of $50 \mathrm{mVs}^{-1}$ and then $10 \mathrm{mVs}^{-1}$ prior to collecting the $\mathrm{X}$-ray data. The $\mathrm{X}$-ray data were collected during potential holds at $0.00 \mathrm{~V}, 0.05 \mathrm{~V}$, and $0.50 \mathrm{~V}$ vs. RHE.

\subsection{X-ray absorption spectroscopy (XAS) and data analysis}

Ex situ measurements were carried out on boron nitride pellets of the as-prepared electrocatalysts under a $\mathrm{H}_{2}$ atmosphere at beamline X23A2, NSLS, Brookhaven National Laboratory. Spectra were collected in transmission geometry at both the Pt $\mathrm{L}_{3}$ $(11564 \mathrm{eV})$ and Pd K $(23450 \mathrm{eV})$ absorption edges. The beamline was equipped with a $\mathrm{Si}(311)$ monochromator with a single bounce harmonic rejection mirror.

In situ XAS measurements were conducted using the fluorescence detection mode at the $\mathrm{Pt} \mathrm{L}_{3}$ and Pd $\mathrm{K}$ absorption edges. The beamlines used to collect the data were: BM26A, ESRF (Si(311) monochromator, two harmonic rejection mirrors, 9-element monolithic Ge detector); X1, HASYLAB, DESY (Si(311) monochromator, harmonic rejection by detuning 65\%, 7 pixel HPGe detector); and B18, Diamond Light Source ( $\mathrm{Si}(311)$ monochromator, harmonic rejection using $\mathrm{Cr}$-coated mirrors at the $\mathrm{Pt}_{\mathrm{L}}$ edge, Ptcoated mirrors at the Pd $\mathrm{K}$ edge). The spectra were collected at 
room temperature in $0.5 \mathrm{M} \mathrm{H}_{2} \mathrm{SO}_{4}$. Data collection was started once the cell current had stabilized following a potential being applied. Pt and Pd reference foils were used to calibrate the incident X-ray energy.

X-ray absorption data were processed and analysed using ATHENA and ARTEMIS respectively, parts of the IFEFFIT software suite [28]. Energy scale calibration was carried out using the reference foil data, with the absorption edge energy $\left(E_{0}\right)$ then set to the first derivative of the sample data. Fits were carried out using a $k$ range of $3-13 \AA^{-1}$ and an $\mathrm{R}$ range of $1.4-3.2 \AA$, with multiple $k$ weightings of 1,2 and 3 . The FEFF input used in these fits was an $f c c$ cluster of a $1: 1 \mathrm{Pt} / \mathrm{Pd}$ alloy, using a lattice parameter of $3.9018 \AA$ taken from the XRD analysis of the PtPd/C alloy. Note that the input is only used to calculate the backscattering phase shifts and amplitude corrections for each scattering path and the use of a 1:1 alloy does not imply that the actual structure of the material must conform to this structure. The $S_{0}^{2}$ value was determined for each edge at each beamline by fitting the reference foil data using the same data range as for the sample data. To minimize the number of variables, $\Delta E_{0}$ was set to be the same for all paths at each absorption edge. The data recorded at both the $\mathrm{Pt} \mathrm{L}_{3}$ and $\mathrm{Pd} \mathrm{K}$ absorption edges were fit simultaneously for each sample. In the fits the shift in bond length $(\Delta R)$ compared to the $1: 1$ alloy used in defining the input parameters and the mean-squared displacement of the bond $\left(\sigma^{2}\right)$ to be the same for the Pd-Pt and Pt-Pd interactions, thereby making the $\mathrm{Pd}-\mathrm{Pt}$ and $\mathrm{Pt}-\mathrm{Pd}$ paths equivalent. The corresponding coordination numbers $N$ were allowed to vary. Differences in the Pt-Pd and $\mathrm{Pd}-\mathrm{Pt}$ coordination numbers should arise, as they are per-atom averages, which are implicit in EXAFS. The Pd atoms in the core below the surface layer and the Pt atoms in the shell beyond the first monolayer, will not have first shell Pt and Pd neighbours, respectively.

\subsection{In situ X-Ray diffraction and data analysis}

In situ XRD patterns were collected on beamline 11-3, Stanford Synchrotron Radiation Lightsource, using a wavelength of $0.9760 \AA$, a MAR345 image plate detector with a pixel size of $150 \mu \mathrm{m}$ and a sample-to-detector distance of $150 \mathrm{~mm}$ calibrated using a $\mathrm{LaB}_{6}$ reference sample. In addition to the catalyst electrodes, XRD data were collected of a carbon electrode, painted from an ink containing the carbon support mixed with the same ratio of Nafion as in the catalyst electrodes, to enable the isolation of the peaks arising from the metal in the samples from those due to the carbon and cell background. As for the in situ EXAFS measurements, the data were collected at room temperature in $0.5 \mathrm{M} \mathrm{H}_{2} \mathrm{SO}_{4}$ and data collection was started once the cell current had stabilized following a potential being applied.

The 2D X-ray diffraction images were integrated radially to give the intensity as a function of $2 \theta$, using the software package Fit2D [29]. The (220) Bragg peak arising from the $f c c$ Pt/Pd nanoparticles was isolated by subtracting a linear background and the $2 \theta$ peak position determined by fitting a Gaussian function using OriginLab 8.1. The error in the peak position was estimated from the shift in the sharp diffraction peak arising from the background at $\sim 46^{\circ} 2 \theta$. The lattice parameter was then obtained for all samples at each potential.

\section{Results and discussion}

The ICP-AES analysis of the Pd@Pt and PtPd alloy catalysts shown in Table 1 confirms that the desired compositions were obtained. The crystallite and particle sizes, respectively, obtained by analysis of both the ex situ XRD (Fig. 1) and TEM images (Fig. 2) are also shown in Table 1. Examination of the particle size
Table 1

Composition and particle size of the catalysts.

\begin{tabular}{|c|c|c|c|c|}
\hline \multirow[t]{2}{*}{ Catalyst } & \multicolumn{2}{|c|}{$\begin{array}{l}\text { ICP-AES Composition/wt.\% } \\
\text { measured (nominal) }\end{array}$} & \multirow{2}{*}{$\begin{array}{l}\text { XRD } \\
\text { crystallite } \\
\text { size/nm }\end{array}$} & \multirow{2}{*}{$\begin{array}{l}\text { TEM mean } \\
\text { particle } \\
\text { size/nm } \\
\text { (no. particles) }\end{array}$} \\
\hline & $\mathrm{Pt}$ & $\mathrm{Pd}$ & & \\
\hline Pd/C Core & & $19.6(20.0)$ & $\mathrm{a}$ & $3.8 \pm 2.1(733)$ \\
\hline $\mathrm{Pd} @ P t_{0.5 \mathrm{ML}}$ & $8.1(8.4)$ & $17.9(17.9)$ & $2.60 \pm 0.06$ & $3.7 \pm 1.4(166)$ \\
\hline $\mathrm{Pd} @ P t_{1 \mathrm{ML}}$ & $16.3(17.1)$ & $16.1(16.3)$ & $2.30 \pm 0.07$ & $3.0 \pm 1.6(83)$ \\
\hline Pd@Pt $4 \mathrm{ML}$ & 38.9 (41.9) & $11.2(11.4)$ & $2.63 \pm 0.05$ & $4.3 \pm 1.3(166)$ \\
\hline $\mathrm{PtPd} / \mathrm{C}$ & $27.6(28.3)$ & $14.8(14.1)$ & $3.13 \pm 0.04$ & $3.8 \pm 1.5(98)$ \\
\hline
\end{tabular}

a Pd phase poorly crystalline.

distributions obtained from the TEM images (Fig. 3) show a loss of the larger particles in the core catalyst (Fig. 3a) upon deposition of $0.5 \mathrm{ML}$ or $1 \mathrm{ML}$ Pt. This suggests that deposition of $\leq 1 \mathrm{ML}$ Pt may cause some fragmentation of the larger Pd particles or agglomerates. The calculated average particle sizes are all similar within the error of measurement as shown in Table 1, with relatively little variation seen in the crystallite sizes obtained from the XRD for the core-shell catalysts.

Cyclic voltammograms of the Pd@Pt catalysts, the Pd/C core catalyst, and a reference $\mathrm{Pt} / \mathrm{C}$ catalyst electrodes in $1 \mathrm{M} \mathrm{H}_{2} \mathrm{SO}_{4}$ at $80^{\circ} \mathrm{C}$ are shown in Fig. 4. The current densities in Fig. 4a for the Pd@Pt electrodes are with respect to the area determined by measuring the charge associated with the monolayer $\mathrm{CO}$ oxidation peaks in Fig. 4c assuming a charge density of $420 \mu \mathrm{C} \mathrm{cm}^{-2}$, which is commonly used as the value for a monolayer of $\mathrm{CO}$ adsorbed on a $\mathrm{Pt}$ surface and corresponds to coverage of one linearly adsorbed CO per Pt surface atom [30]. The actual CO:surface metal atom ratio is likely to deviate from this value, especially for a pure Pd surface where $\mathrm{CO}$ is more likely be adsorbed at bridge-bonded sites, giving a CO:Pd ratio of 1:2 [31]. This may explain the apparent increased current density across the entire potential range for the normalised voltammogram (via under estimation of the area used in the normalisation) for the $0.5 \mathrm{ML}$ sample, which has a surface with a mixed composition.

The composition of the catalyst particles has a marked effect on the oxide formation and stripping and the CO monolayer oxidation peaks. Increasing deposition of Pt yields cyclic voltammograms that appear increasingly more Pt-like, especially for the oxide formation and stripping region (Fig. 4a and b), with the alloy catalyst displaying behaviour between that of the $1 \mathrm{ML}$ and $4 \mathrm{ML}$ core-shell catalysts. The peaks in the hydrogen adsorption and desorption peaks are broad and poorly defined for all of the bimetallic catalysts, with no clear trends readily observed, although comparison with the $\mathrm{CVs}$ for the $\mathrm{Pt} / \mathrm{C}$ reference and $\mathrm{Pd} / \mathrm{C}$ core catalyst indicates that the $0.5 \mathrm{ML}$ displays Pd-like characteristics whereas the $4 \mathrm{ML}$ is distinctly more Pt-like.

In situ EXAFS data and the corresponding Fourier transforms obtained for the core Pd/C catalyst (Fig. 5) and the Pt/C reference catalyst (Fig. S3) as a function of the applied potential are shown along with the model spectra obtained by fitting the first coordination shell (fitting parameters are summarised in Tables S1 and S2). Hydride formation for the $\mathrm{Pd} / \mathrm{C}$ catalyst is observed at $0.0 \mathrm{~V}$, as evidenced by the increase in the Pd-Pd distance to $2.83 \AA$ from $2.76 \AA$ at $0.07 \mathrm{~V}$ and $2.74 \AA$ at $0.52 \mathrm{~V}$, in agreement with the previous EXAFS study by Rose et al. [32]. The lattice parameters for the Pd particles, calculated by assuming retention of the $f c c$ lattice, are $3.999 \AA, 3.903 \AA$, and $3.876 \AA$, respectively, at the three potentials $(0.0 \mathrm{~V}, 0.07 \mathrm{~V}$, and $0.52 \mathrm{~V})$, indicating that a mixture of the $\alpha$ and $\beta$ phases was formed at $0.07 \mathrm{~V}$ and the $\beta$-phase at $0.0 \mathrm{~V}[19,33-36]$. In contrast, adsorption of hydrogen on the surface of the Pt/C catalyst particles results in a negligible increase in the $\mathrm{Pt}-\mathrm{Pt}$ distance 
a

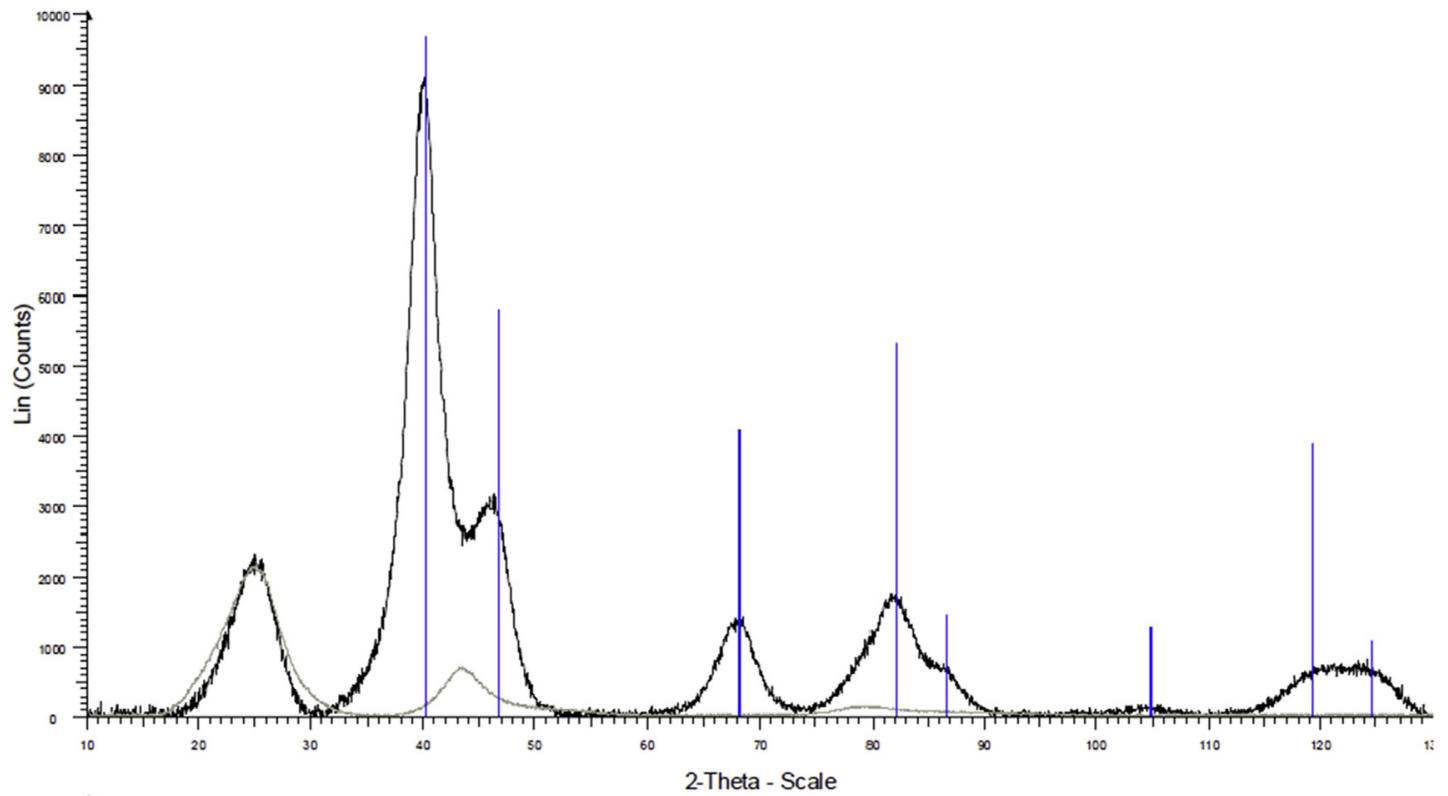

b

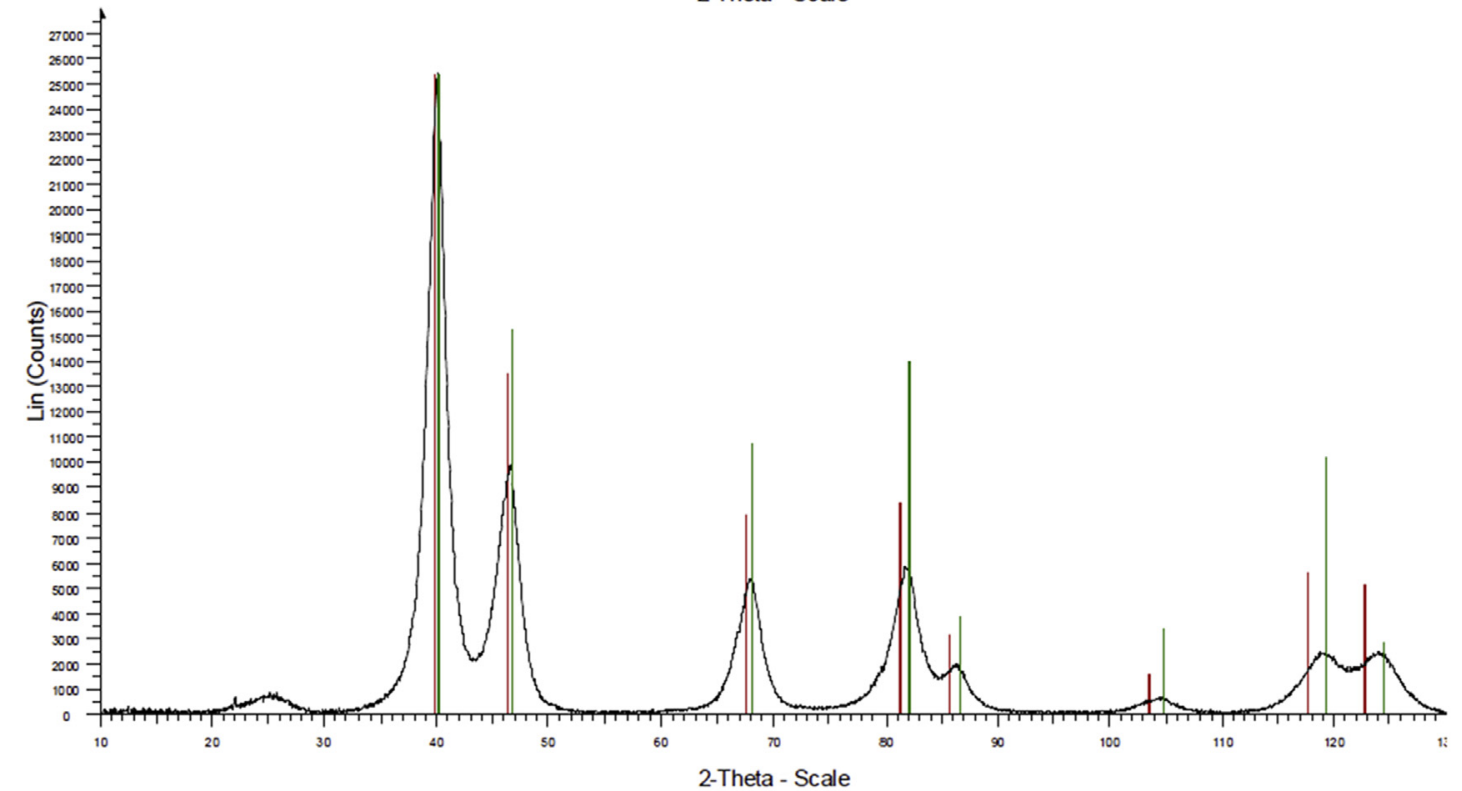

c

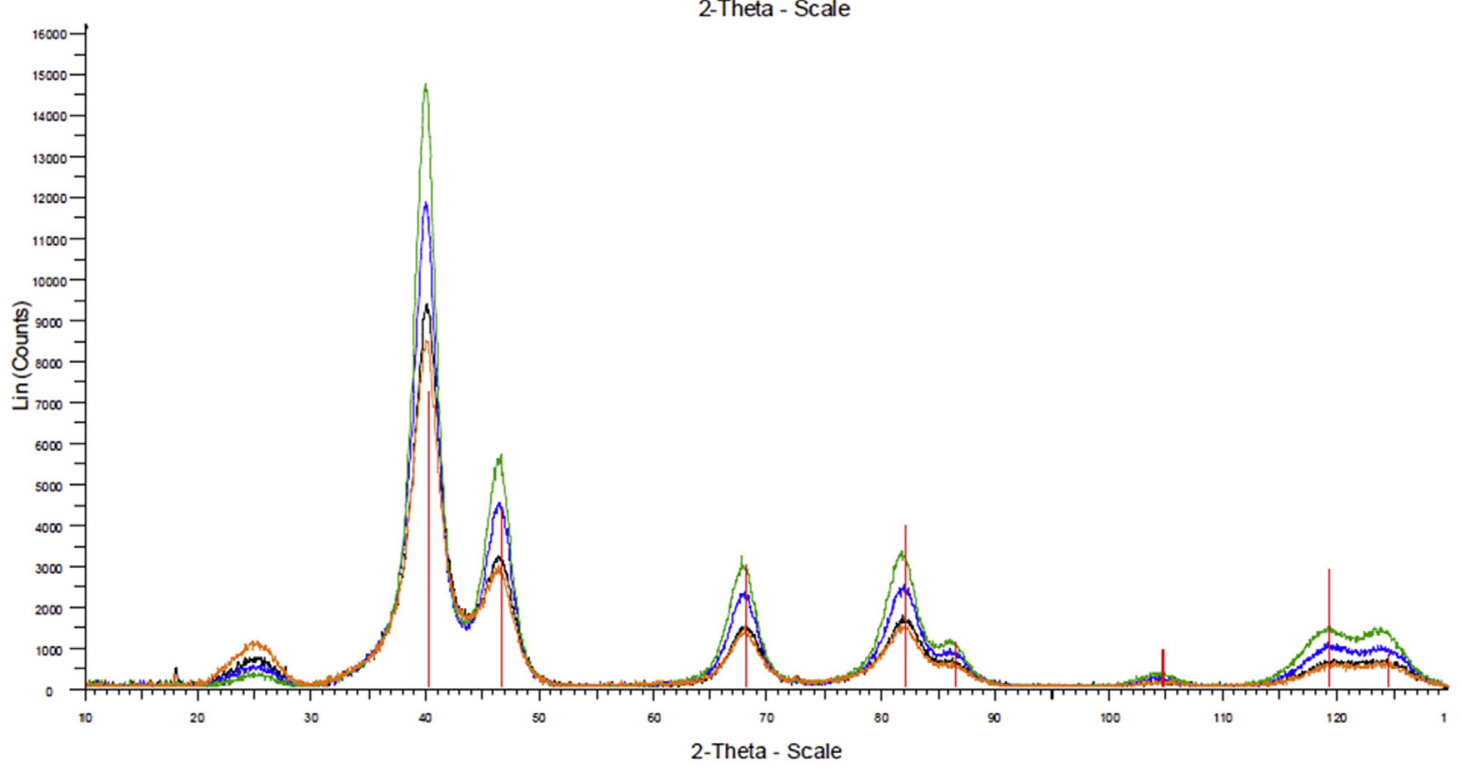

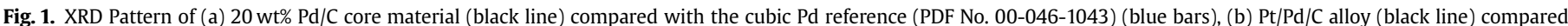

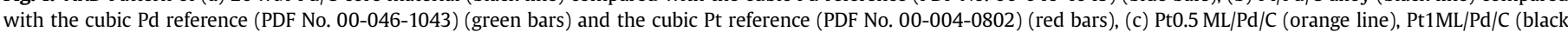

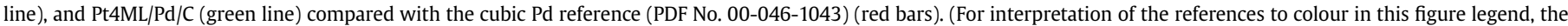
reader is referred to the Web version of this article.) 
a)

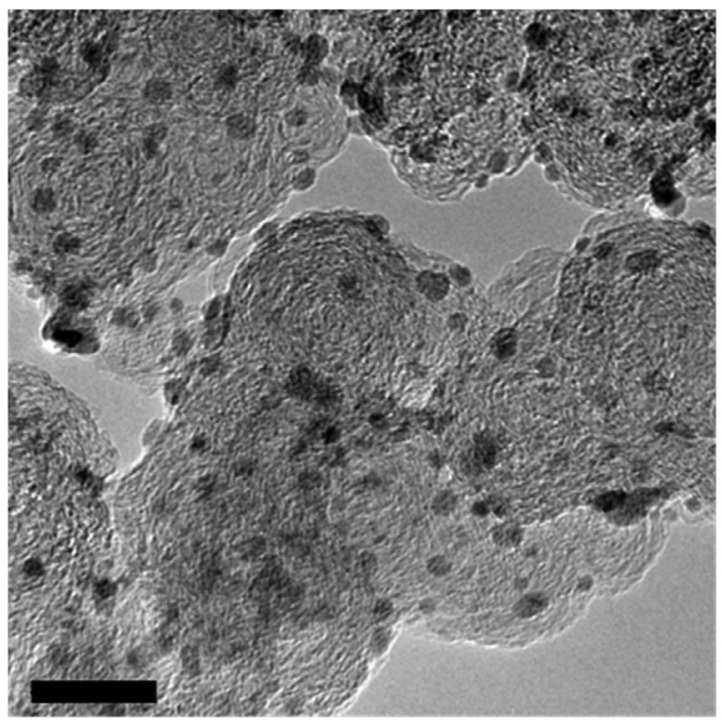

c)

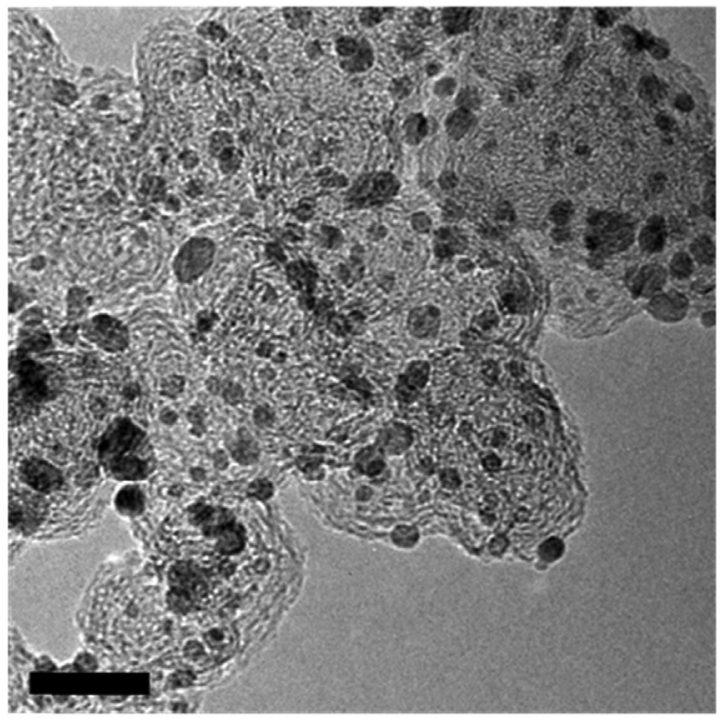

e)

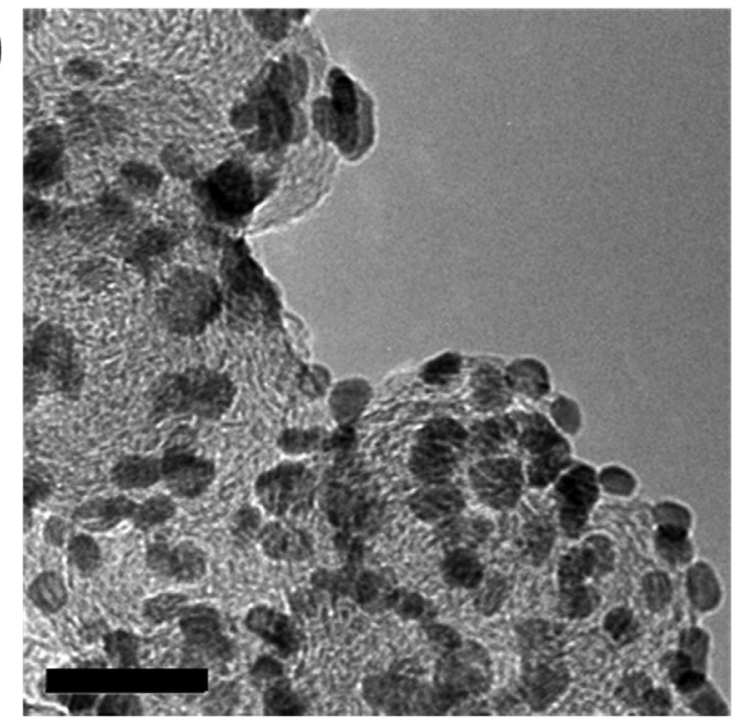

b)

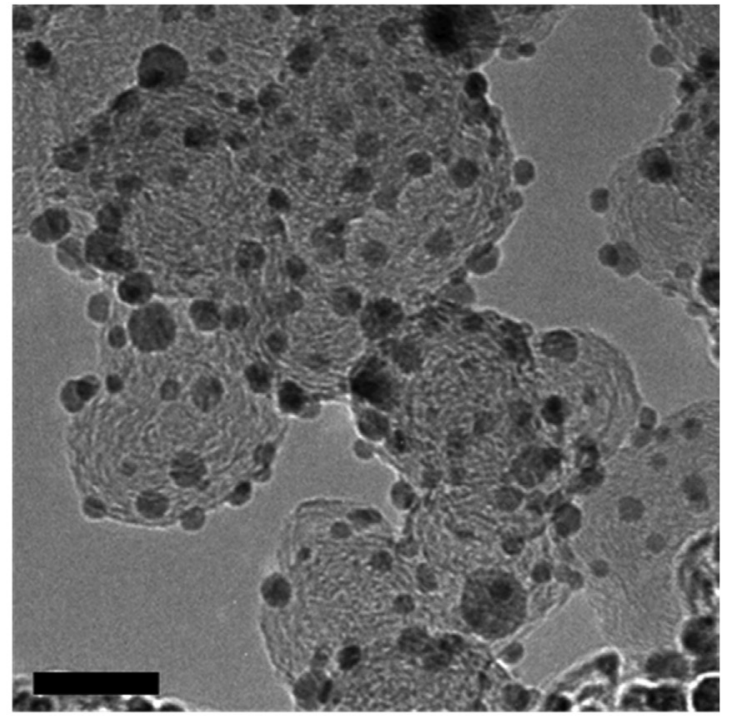

d)

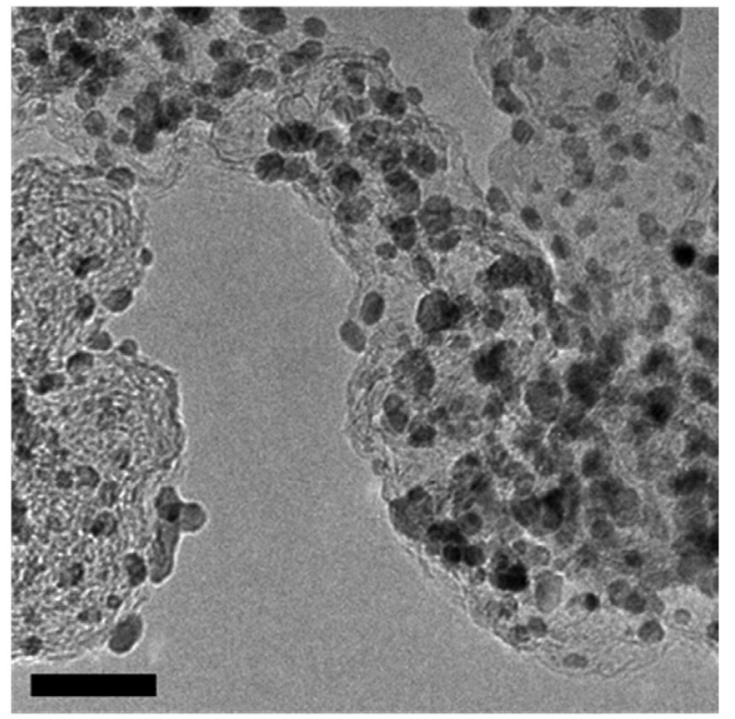

Fig. 2. TEM micrographs of (a) $\mathrm{Pd} / \mathrm{C}$ core material, (b) $\mathrm{Pt} / \mathrm{Pd} / \mathrm{C}$ alloy, (c) $\mathrm{Pt}_{0.5 \mathrm{ML}} / \mathrm{Pd} / \mathrm{C}$, (d) $\mathrm{Pt}_{1 \mathrm{ML}} / \mathrm{Pd} / \mathrm{C}$ and (e) $\mathrm{Pt}_{4 \mathrm{ML}} / \mathrm{Pd} / \mathrm{C}$, where the scale bar represents $20 \mathrm{~nm}$. 
a)

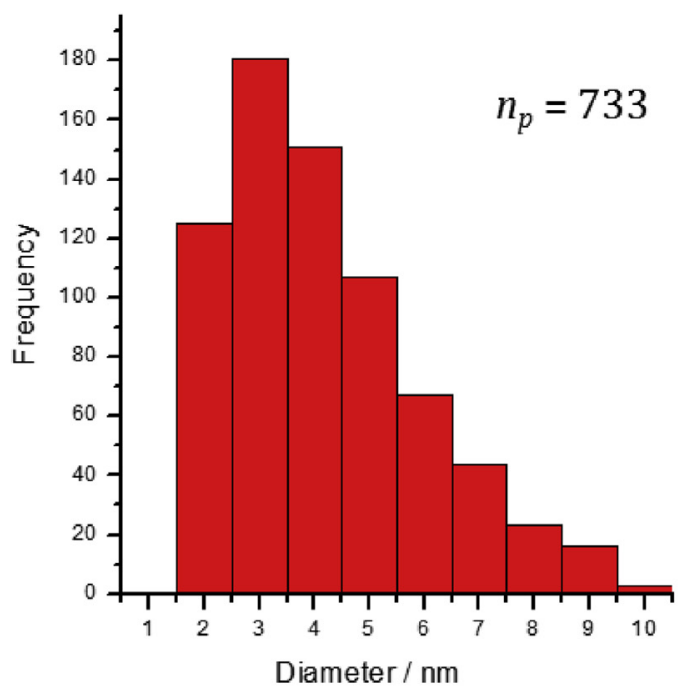

c)

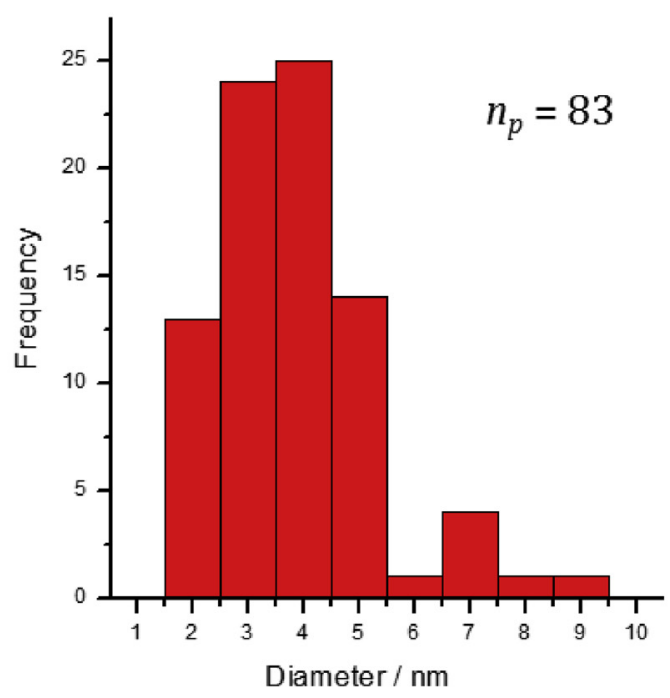

e)

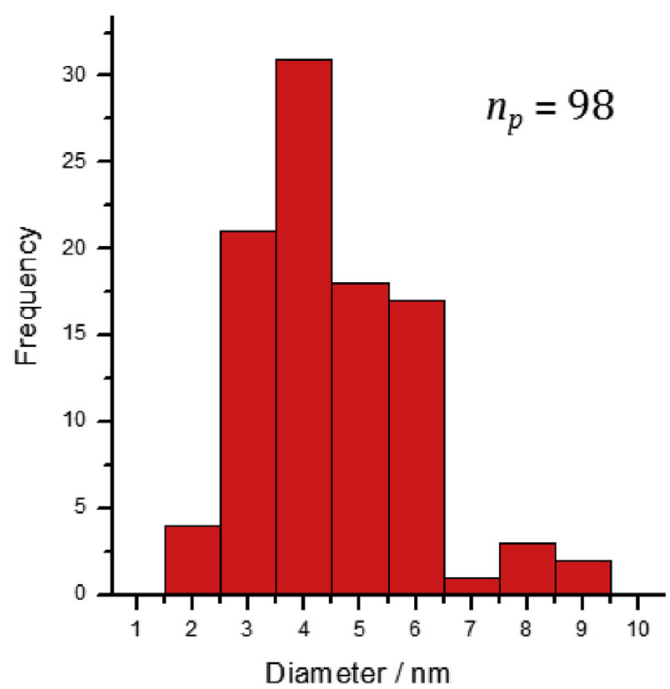

b)

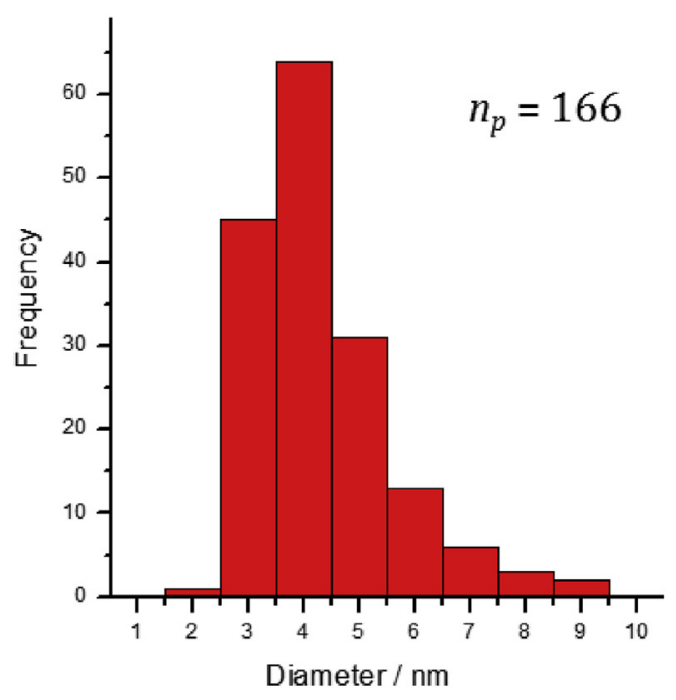

d)

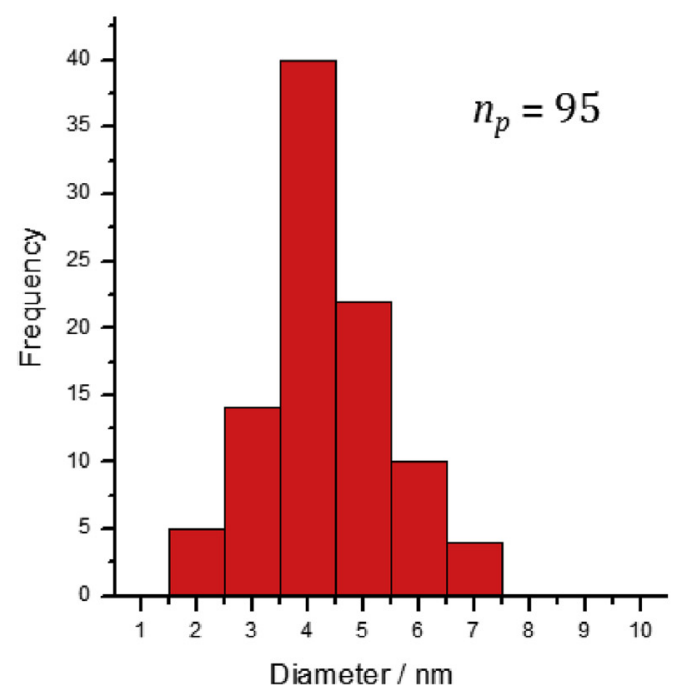

ig. 3. Histograms obtained from TEM of the fresh catalysts (a) Pd/C core material, (b) Pt/Pd/C alloy, (c) $\mathrm{Pt}_{0.5 \mathrm{ML}} / \mathrm{Pd} / \mathrm{C}$, (d) $\mathrm{Pt}{ }_{1 \mathrm{ML}} / \mathrm{Pd} / \mathrm{C}$ and (e) $\mathrm{Pt} 4 \mathrm{ML} / \mathrm{Pd} / \mathrm{C}$. 

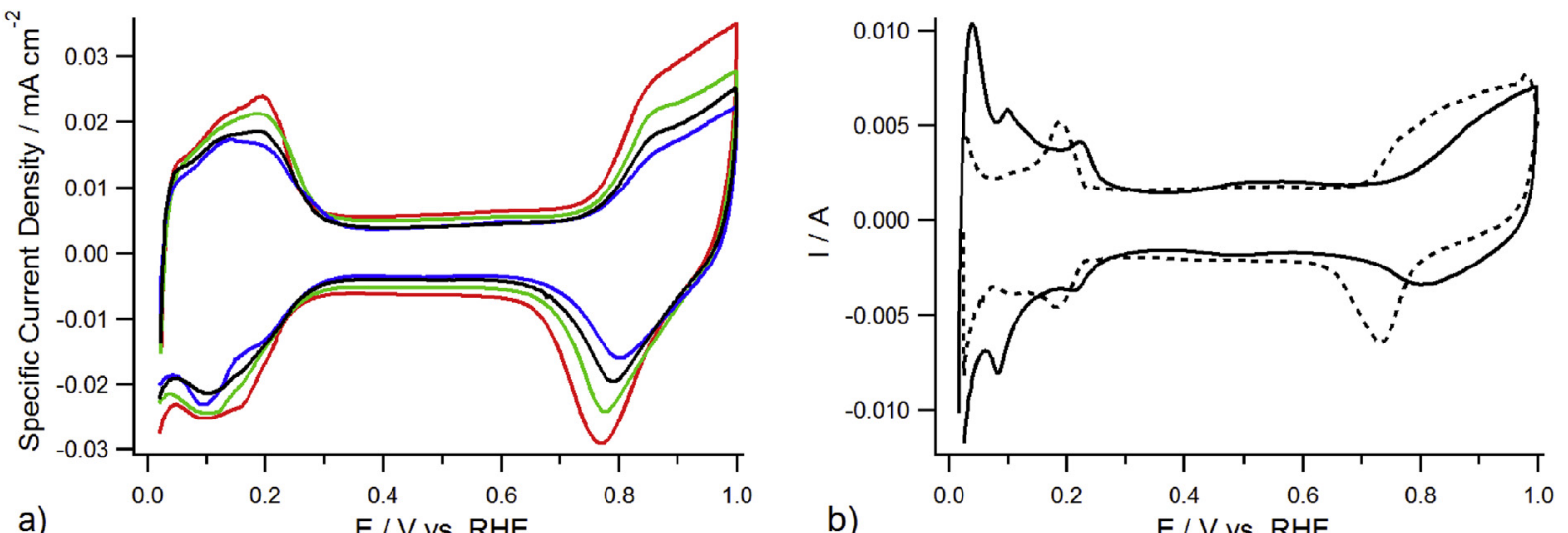

b)

E / V vs. RHE
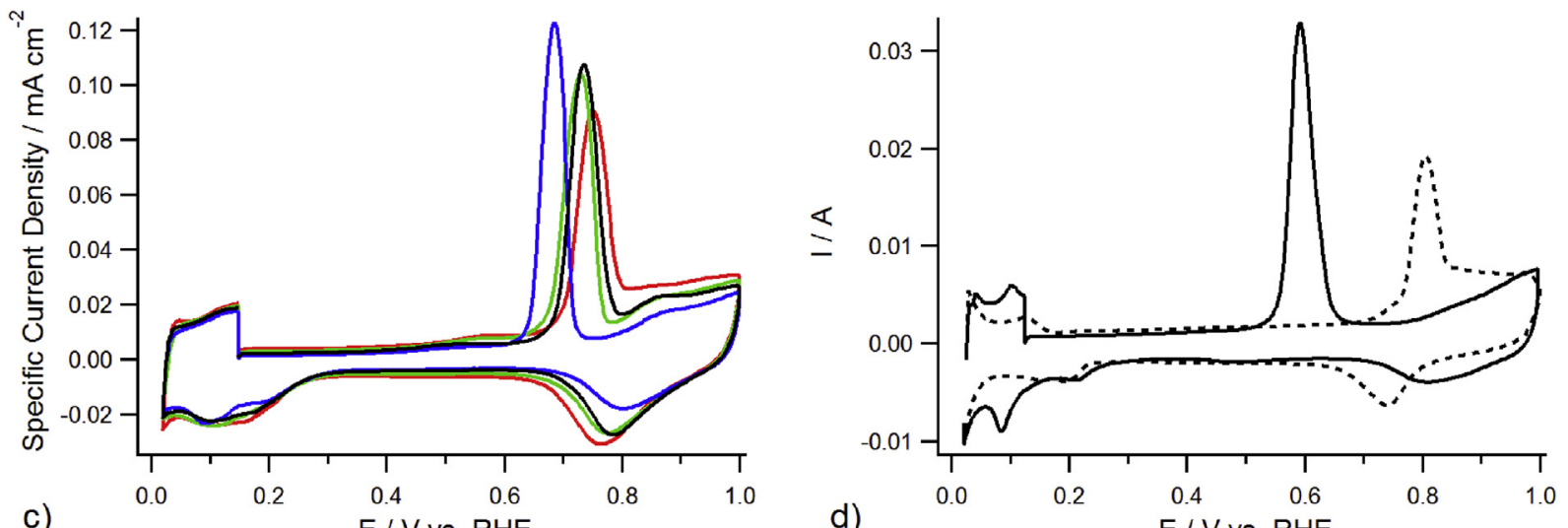

Fig. 4. Cyclic voltammograms of the catalyst electrodes in $80^{\circ} \mathrm{C} 1 \mathrm{~mol} \mathrm{dm}^{-3} \mathrm{H}_{2} \mathrm{SO}_{4}$ at $10 \mathrm{mV} \mathrm{s}^{-1}$. (a) and (b) in nitrogen purged solution, (c) and (d) first cycles after exposure to CO at $0.15 \mathrm{~V}$ vs. RHE as described in the text. (a) and (c) Pd@Pt $0.5 \mathrm{ML}$ red, $1 \mathrm{ML}$ green, $4 \mathrm{ML}$ blue, and alloy black lines. (b) and (d) Pd core catalyst dashed line, $40 \mathrm{wt} \% \mathrm{Pt} / \mathrm{C}$ reference catalyst solid line. (For interpretation of the references to colour in this figure legend, the reader is referred to the Web version of this article.)

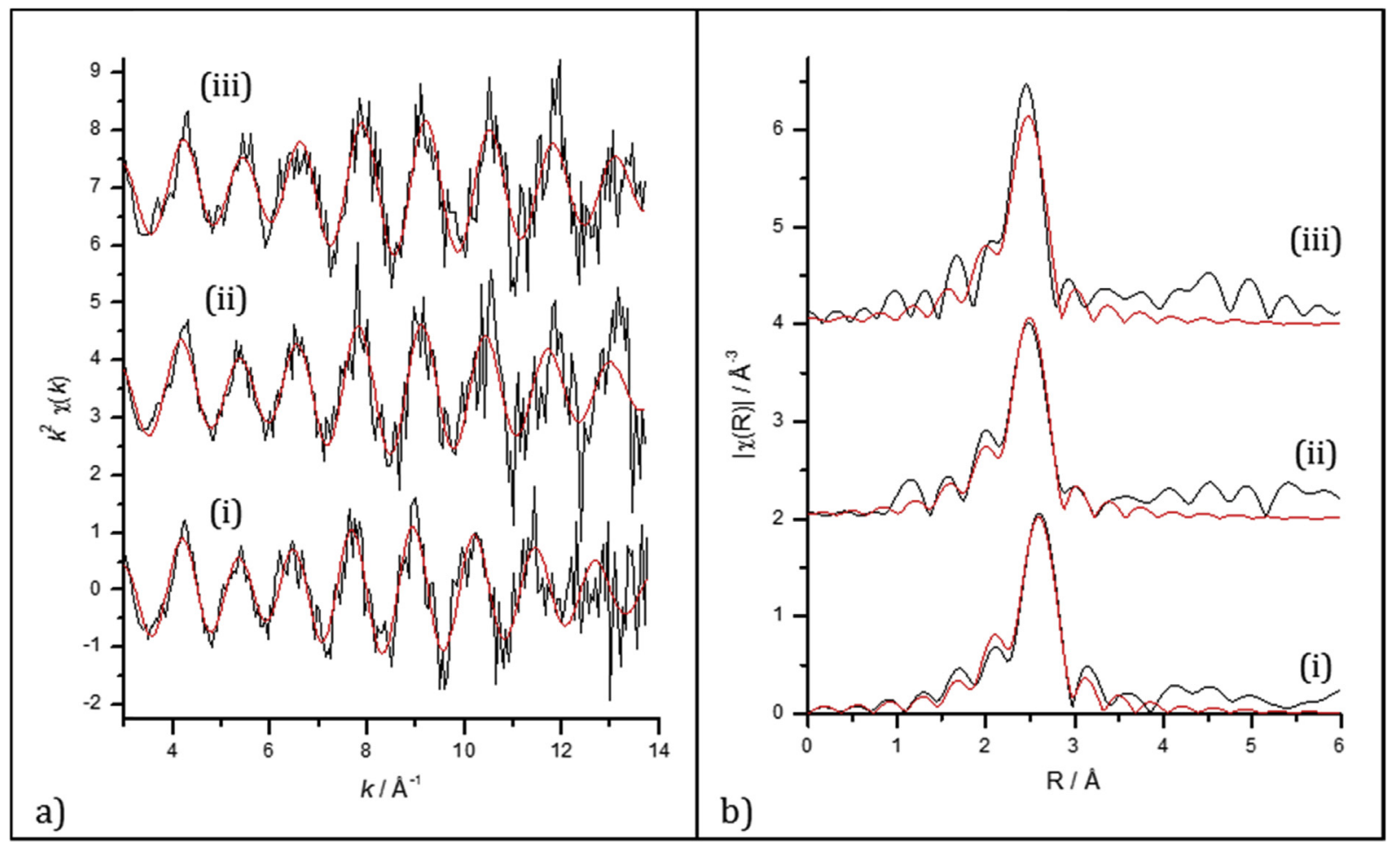

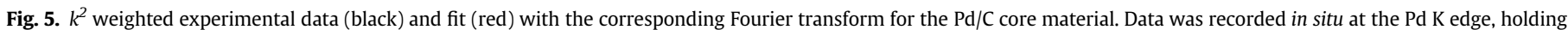

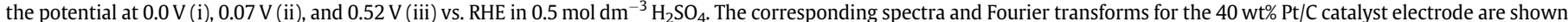
in the supplementary information (Fig. S3). (For interpretation of the references to colour in this figure legend, the reader is referred to the Web version of this article.) 
(within the error of the fits of the EXAFS data), indicating that hydrogen is not incorporated into the lattice of the Pt nanoparticles.

The in situ Pt $\mathrm{L}_{3}$ and Pd K edge EXAFS data and Fourier transforms obtained for the Pd@Pt $\mathrm{t}_{0.5 \mathrm{ML}}$ core-shell catalyst are shown in Fig. 6 to illustrate the data quality, with those for the other coreshell and PtPd/C alloy catalysts shown in Figs. S4-S6. The first shell fitting parameters for all the core-shell particles at each potential at both edges are summarised in Table S3. The coordination numbers obtained are in excellent agreement with the ex situ results published previously for similar catalysts [23] show that the core-shell structure is retained upon immersion of the catalyst electrodes in the $\mathrm{H}_{2} \mathrm{SO}_{4}$ solution, in that $\mathrm{Pd}$ is in a Pd rich environment, whilst Pt is in a Pt rich environment. Taking the 1 monolayer catalyst as an example, the first shell coordination

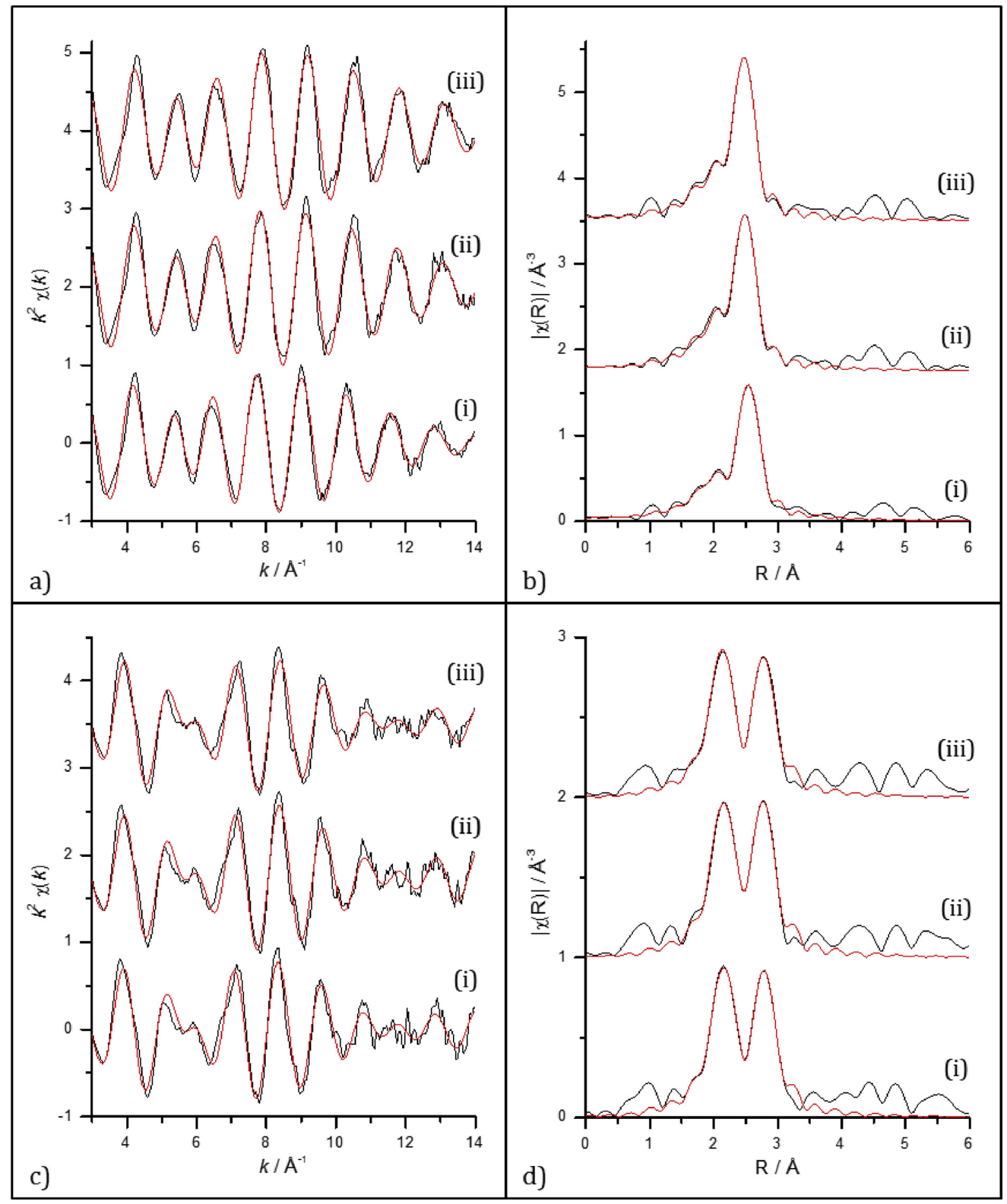

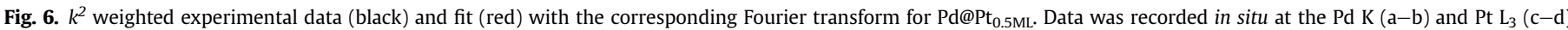

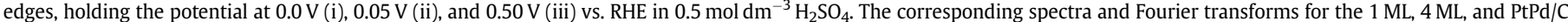

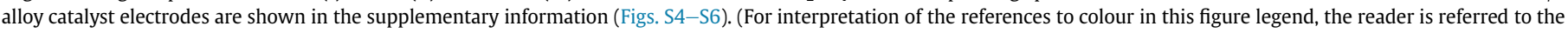
Web version of this article.) 


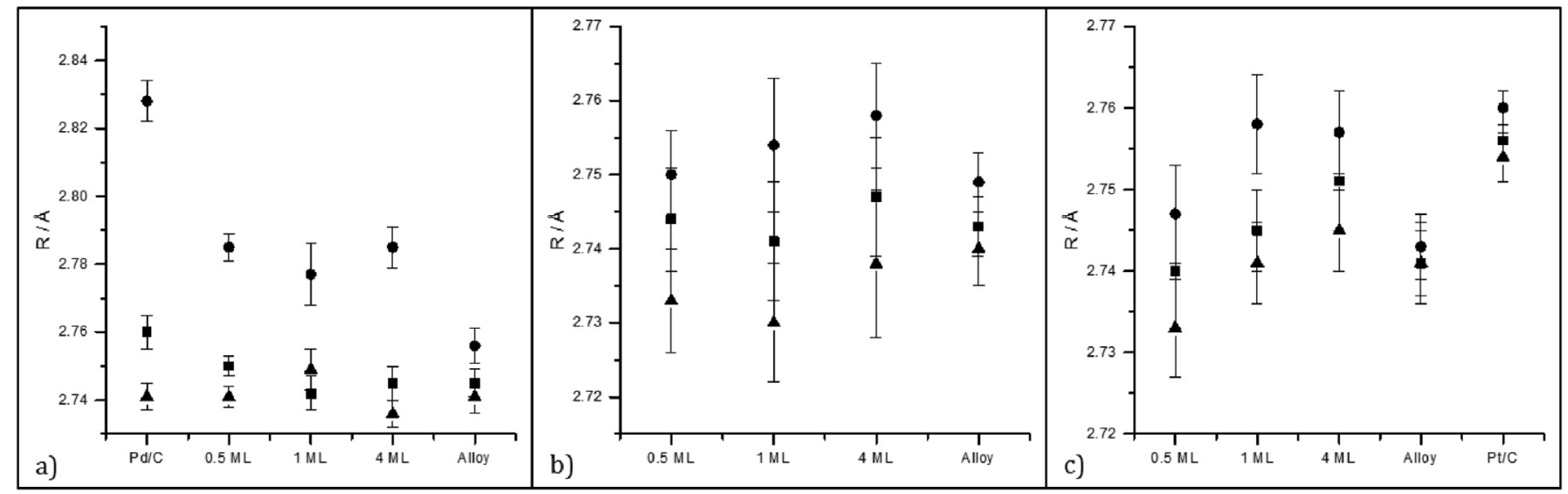

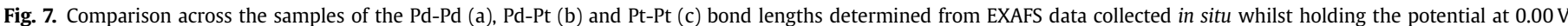
(circles), $0.05 \mathrm{~V}$ (squares) and $0.50 \mathrm{~V}$ (triangles) vs. RHE.

number of 9.6 at $0.52 \mathrm{~V}$ suggests that the average particle contains $309 \mathrm{Pd}$ atoms, assuming a cuboctahedral particle shape as described by Benfield [37]. A perfect 1 monolayer core shell catalyst would then have a Pt-Pt coordination number of 4.4, Pt-Pd of 3.3, and $\mathrm{Pd}-\mathrm{Pt}$ of 1.7 . The corresponding coordination numbers obtained by fitting the EXAFS data (shown in Table S3) of 7.8, 2.7, and 1.3 , along with the decrease in the Pd-Pd coordination number to 7.5 , suggest both some change in the particle shape and clustering of the Pt on the surface of core catalyst particles. Detailed further analysis of the core-shell structure based on the EXAFS fitting parameters is not justified given the particle size distribution of the core catalyst particles. However, comparison of the fitting parameters obtained for the $4 \mathrm{ML}$ catalyst by examining the ratio of $\mathrm{N}(\mathrm{Pd}-\mathrm{Pt}): \mathrm{N}(\mathrm{Pd}-\mathrm{Pd})$, which is 0.58 compared to 0.15 and 0.17 for the $0.5 \mathrm{ML}$ and $1 \mathrm{ML}$ catalysts, respectively, suggests greater mixing of the two elements at the core-shell interface for this catalyst, but not to the extent that the well mixed alloy phase has been formed. In comparison, the fully mixed/alloy catalyst has a $\mathrm{N}(\mathrm{Pd}-\mathrm{Pt}): \mathrm{N}(\mathrm{P}-$ $\mathrm{d}-\mathrm{Pd}$ ) ratio of 1.2. Such interfacial mixing has previously been reported by Liu et al. [38], who investigated Pt@Pd and Pd@Pt catalyst particles with a narrow particle size distribution and Pt:Pd ratio of $1: 1$, enabling a detailed model of the extent of interfacial mixing to be proposed based on the analysis of their EXAFS data.

The effects of applied potential on the Pd-Pd, Pd-Pt, and Pt-Pt distances for all the catalyst electrodes are illustrated graphically in Fig. 7. Changing the potential from $0.5 \mathrm{~V}$ to $0.05 \mathrm{~V}$ is accompanied by a small increase in all of the coordination distances. The exceptions being the Pd-Pd distance for the $1 \mathrm{ML}$ catalyst, for which there is a slight reduction in the distance (although this is within the error of the fit), and the Pt-Pt distance for the alloy catalyst, for which no change was observed. Holding the potential at $0.0 \mathrm{~V}$ is accompanied by a larger increase in the coordination distances, especially the Pd-Pd distance (Fig. 7a) indicating hydride formation in the Pd core.

The effects of hydride formation were also investigated using in situ XRD. The isolated (220) diffraction peaks for the Pd@Pt coreshell catalysts along with the PtPd/C alloy, and the $\mathrm{Pd} / \mathrm{C}$ core catalyst, are shown in Fig. 8. The full XRD data range for the PtPd/C alloy catalyst electrode at $0.5 \mathrm{~V}$ along with that of the carbon only electrode are shown in the supplementary information (Fig. S7). The formation of the mixed $\alpha$ - and $\beta$-phase at $0.05 \mathrm{~V}$ (blue line) and $\beta$-hydride at $0.0 \mathrm{~V}$ (red line) are clearly observed for the $\mathrm{Pd} / \mathrm{C}$ core catalyst as a shift in the position of the (220) diffraction peak (Fig. 8a) to a smaller $2 \theta$ value from that at $0.5 \mathrm{~V}$ (black line). A small shift is observed in the peak position for the 0.5 ML sample, accompanied by a broadening on the low $2 \theta$ side, indicating the formation of some of the pure $\beta$-phase, which may be present either in the core of the modified particle or may indicate that some of the Pd particles were not covered by Pt at such a low coverage. Smaller or negligible shifts are observed for the other Pd@Pt and $\mathrm{PtPd} / \mathrm{C}$ alloy catalysts, indicating that hydride formation was restricted to the mixed phase, without any pure $\beta$-phase being formed [39].

The lattice parameters obtained by fitting the (220) peak are summarised in Table 2 along with those calculated from the Pd-Pd coordination distance obtained from the fits of the EXAFS data. Differences in the values of the lattice parameters determined via XRD and EXAFS parameters may be attributed to the fact that XRD is a volume average technique with a bias towards larger more crystalline particles, whilst EXAFS is a per-atom technique in which atoms in crystalline and amorphous environments contribute equally. Nevetheless, the same trends with increasing potential are observed. The lattice parameters obtained using both the XRD and EXAFS data show that the extent of hydride formation at $0.0 \mathrm{~V}$ for all of the Pd@Pt catalysts is much less than that observed for the Pd/ $C$ core catalyst electrode, being limited to formation of the mixed $\alpha$ and $\beta$-phase.

The effects of a Pd@Pt core-shell structure on the hydrogen storage (hydride phase formation) have been reported by Yamauchi et al. at the gas/solid interface, using unsupported nanoparticles, consisting of a $6 \mathrm{~nm}$ diameter core with a $2 \mathrm{~nm}$ thick Pt shell (approximately $7 \mathrm{ML}$ ), exposing them to $\mathrm{H}_{2}(\mathrm{~g})$ at various elevated pressures at $300 \mathrm{~K}$ [18]. Their baseline measurements of Pd core nanoparticles showed that the lattice parameter increased to $4.00 \AA$ upon exposure to $\mathrm{H}_{2}(\mathrm{~g})$ at $1.01 \times 10^{5} \mathrm{~Pa}$, corresponding to formation of the $\beta$-phase. In contrast, no apparent change in the in situ XRD patterns accompanied either an increase or decrease in the $\mathrm{H}_{2}$ (g) pressure for the Pd@Pt core-shell particles, although the hydrogen adsorbed by the particles yielded a $\mathrm{H} / \mathrm{M}$ (hydrogen to metal atomic ratio) of 0.23 at $1.01 \times 10^{5} \mathrm{~Pa} \mathrm{H}_{2}$, indicating that the pure $\beta$-phase was not achieved. In this same study, Yamauchi et al. used solid state ${ }^{2} \mathrm{H}$ NMR to determine the location of the adsorbed hydrogen, finding that hydrogen atoms were present throughout the Pd@Pt particles (dispersed inside both the Pt and Pd lattices), but were present at a larger concentration at the core/shell boundary. If any such preferential location occurs in our electrochemical study, it should be apparent in the EXAFS data as either a larger relative increase in the $\mathrm{Pt}-\mathrm{Pd}$ distance, compared to that observed for the Pd-Pd distance (see Fig. 7 and Table S3), or as an increase in the disorder $\left(\sigma^{2}\right)$ term for the Pt-Pd and $\mathrm{Pd}-\mathrm{Pt}$ 


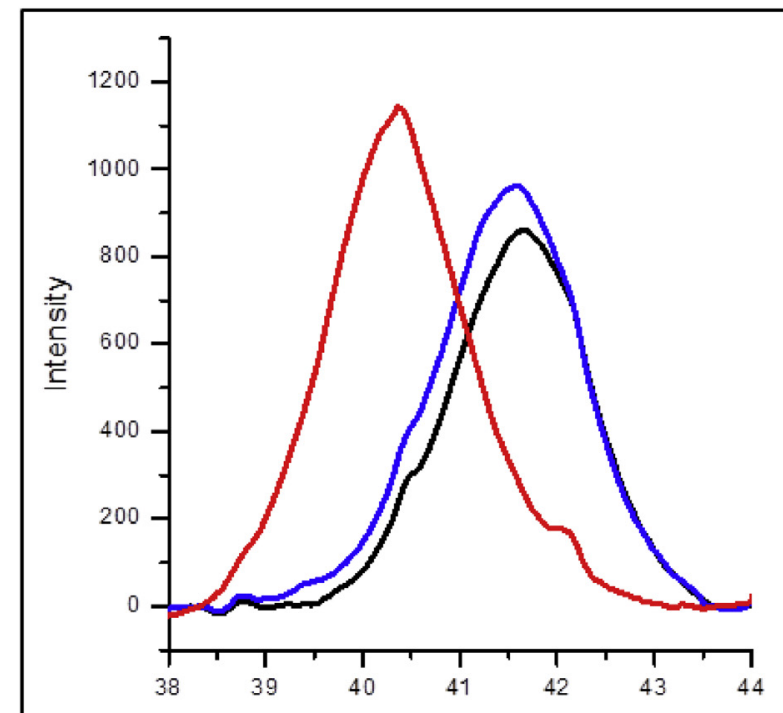

a)

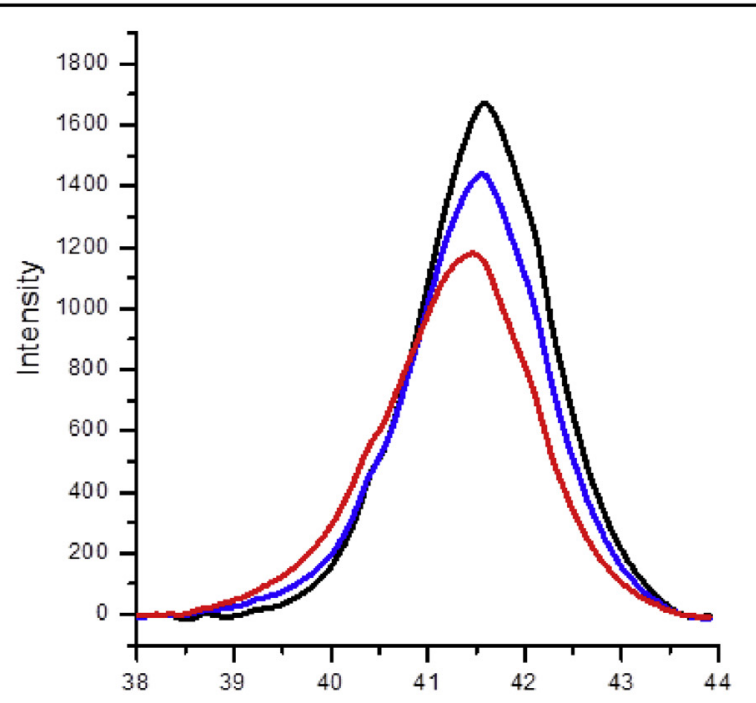

b)

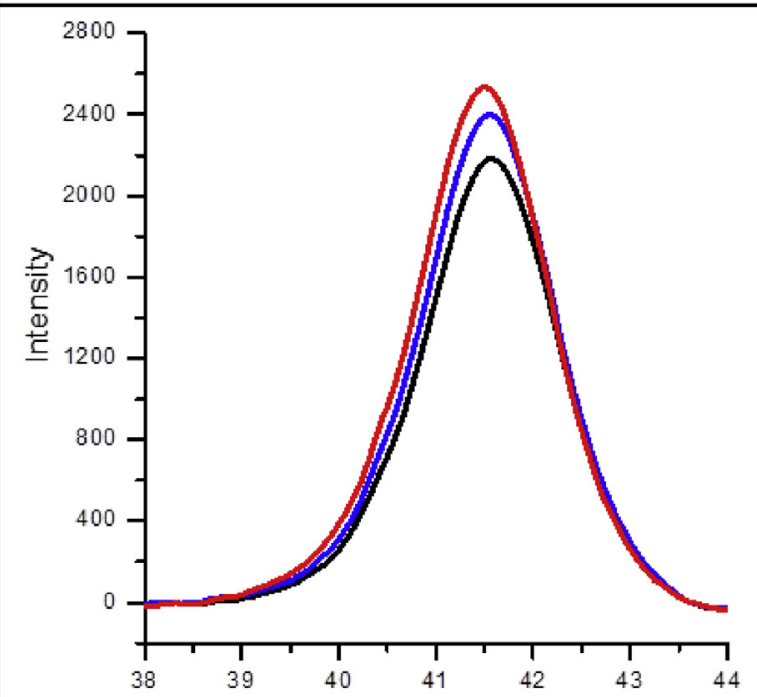

c)

$2 \theta / \circ$
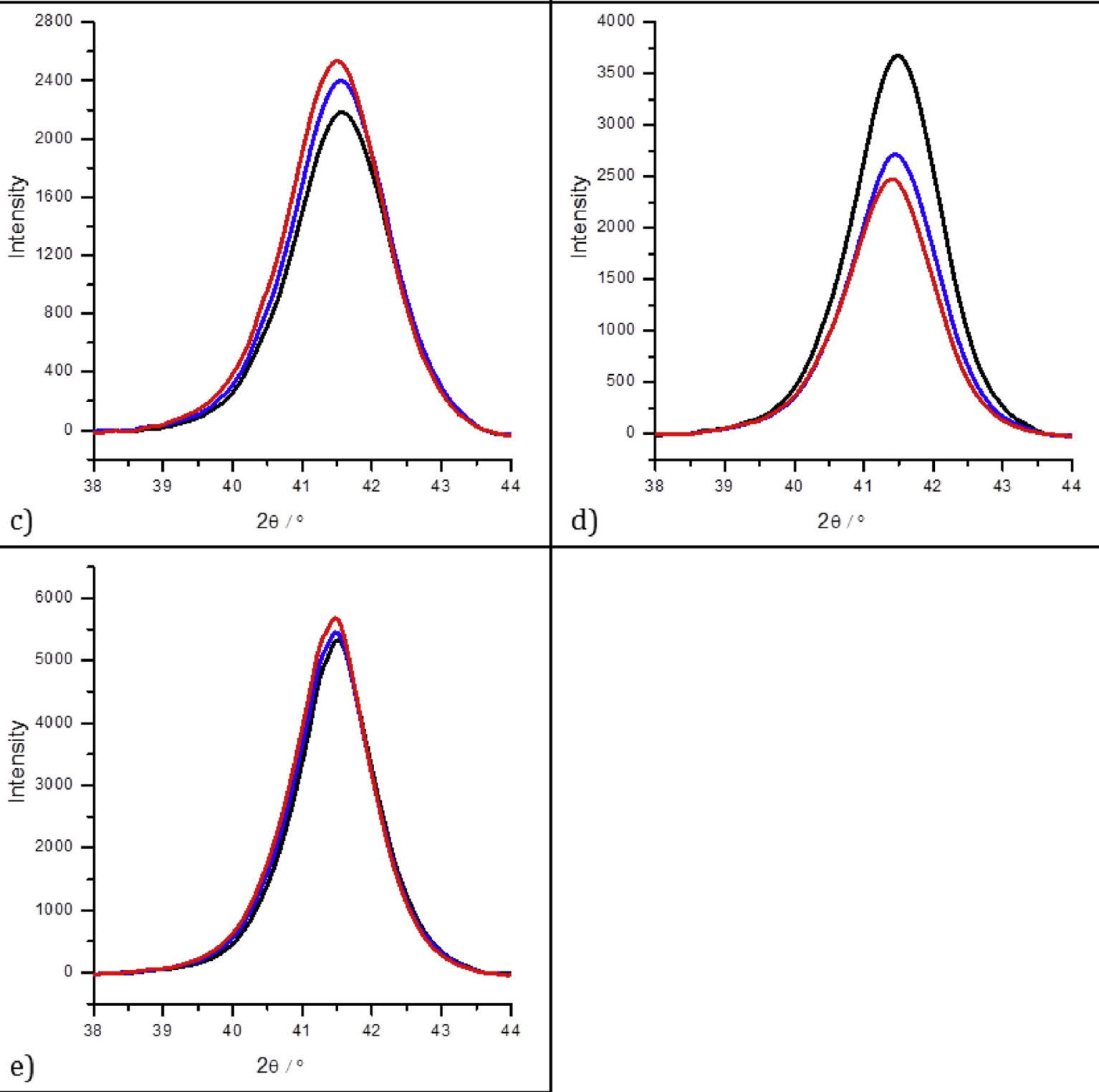

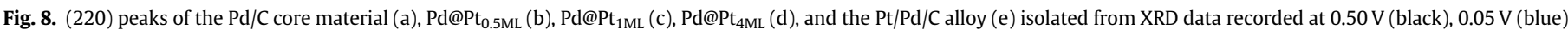

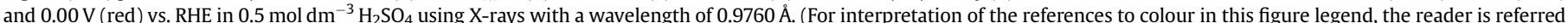
to the Web version of this article.) 
Table 2

Lattice parameters obtained by fitting the (220) Bragg peaks from the in situ XRD data (XRD) and calculated from the Pd-Pd coordination distance from the EXAFS fits for the catalyst electrodes in $0.5 \mathrm{~mol} \mathrm{dm}^{-3} \mathrm{H}_{2} \mathrm{SO}_{4}$. Errors in the values from the XRD are $\pm 0.002 \AA$, whilst those from the EXAFS data are $\pm 0.006 \AA$.

\begin{tabular}{|c|c|c|c|c|c|c|}
\hline \multirow{3}{*}{$\begin{array}{l}\text { V vs. RHE } \\
\overline{\text { Method }}\end{array}$} & \multicolumn{6}{|l|}{$\mathrm{a} / \AA \AA$} \\
\hline & \multicolumn{2}{|l|}{0.50} & \multirow{2}{*}{$\frac{0.07}{\mathrm{XRD}}$} & \multirow{2}{*}{$\frac{0.05}{\text { EXAFS }}$} & \multicolumn{2}{|l|}{0.00} \\
\hline & XRD & EXAFS & & & XRD & EXAFS \\
\hline Pd/C Core & 3.885 & 3.84 & 3.895 & 3.90 & 4.002 & 4.00 \\
\hline${\mathrm{Pd} @ P t_{0.5 \mathrm{ML}}}$ & 3.889 & 3.84 & 3.895 & 3.89 & 3.910 & 3.94 \\
\hline $\mathrm{Pd} @ P t_{1 \mathrm{ML}}$ & 3.891 & 3.89 & 3.893 & 3.88 & 3.898 & 3.93 \\
\hline${\mathrm{Pd} @ \mathrm{Pt}_{4 \mathrm{ML}}}$ & 3.899 & 3.87 & 3.902 & 3.88 & 3.907 & 3.94 \\
\hline $\mathrm{PtPd} / \mathrm{C}$ & 3.898 & 3.84 & 3.901 & 3.88 & 3.903 & 3.90 \\
\hline
\end{tabular}

coordination shells at $0.0 \mathrm{~V}$ compared to $0.50 \mathrm{~V}$ (see Table S3). Neither of these effects are observed (the Pt-Pd distance was found to increase by a smaller amount than the Pd-Pd for all of the coreshell catalysts and any variation in $\sigma^{2}$ was within the error of the fit) and it thus seems unlikely that such preferential location is found in the electrochemically produced hydride catalyst particles.

There have been many studies of the adsorption and absorption of hydrogen at and in metal electrodes and these were extensively reviewed in 1998 by Jerkiewicz [40]. Adsorbed hydrogen, either under-potential, $\mathrm{H}_{\mathrm{upd}}$, or over-potential, $\mathrm{H}_{\mathrm{opd}}$, dependent on the metal surface, are generally considered as intermediates in the formation of the hydride [41,42]. For polycrystalline $\mathrm{Pd}$ in $0.5 \mathrm{~mol} \mathrm{dm}^{-3} \mathrm{H}_{2} \mathrm{SO}_{4}$, Jerkiewicz reported an electrode process attributed to hydrogen absorption at $0.3 \mathrm{~V}$ vs. RHE in the cyclic voltammograms, which is positive of the HER, and concluded that it is the $\mathrm{H}_{\text {upd }}$ that undergoes interfacial transport into "clean" Pd [40]. In contrast the $\mathrm{H}_{\text {upd }}$ peak was absent in the voltammetry of $\mathrm{Pd}-\mathrm{Pt}$ alloys as reported by, Grden et al., who concluded that $\mathrm{H}_{\mathrm{opd}}$ participates in the hydrogen absorption process [43].

The effects of a Pt overlayer on the energetics of hydrogen adsorption and absorption (hydride formation) have been explored by Kandoi et al. [44] using density functional theory (DFT) calculations. They showed that the barrier to formation of sub-surface (absorbed) hydrogen is $0.35 \mathrm{eV}$ for unmodified Pd, $0.38 \mathrm{eV}$ for a Pt monolayer on a Pd substrate, and $0.69 \mathrm{eV}$ for unmodified Pt. On the basis of these calculations, the presence of a monolayer of Pt is unlikely to represent a significant increase in the barrier to hydride formation.

The effects of Pt deposition on Pd hydride have been reported in an experimental study by Bartlett and Marwan, who investigated nanostructured thin film Pd electrodes modified by $0,0.1$, and 0.3 monolayers of $\mathrm{Pt}$ [45]. Their voltammograms obtained in $1 \mathrm{~mol} \mathrm{dm}^{-3} \mathrm{H}_{2} \mathrm{SO}_{4}$ showed a clear separation of the $\mathrm{H}_{\text {upd }}, \mathrm{H}_{\mathrm{abs}}$, and hydrogen evolution reaction (HER) processes. Coverage by Pt, even as little as $0.1 \mathrm{ML}$, resulted in suppression of the $\mathrm{H}_{\text {upd }}$ peak. At the same time the rates of the formation of the hydride and hydrogen evolution reactions were both enhanced. Thus, they concluded that $\mathrm{H}_{\text {upd }}$ acts as a barrier to hydrogen absorption and that such absorption occurs in a single step and neither $\mathrm{H}_{\text {upd }}$ nor $\mathrm{H}_{\mathrm{opd}}$ are intermediates in the process.

In agreement with the study by Bartlett and Marwan [45], the voltammogram for the Pd/C electrode shown in Fig. 4b shows a well separated $\mathrm{H}_{\text {upd }}$ peak at $0.2 \mathrm{~V}$ vs. RHE and for the Pd@Pt core-shell catalysts this peak is less distinct. For the Pd@Pt $4 \mathrm{ML}$ catalyst the voltammogram more closely resembles the two characteristic $\mathrm{H}_{\mathrm{ads}}$ peaks of Pt, as discussed above. The difficulties in normalising the Pd@Pt ${ }_{0.5 \mathrm{ML}}$ data for the ECSA of the catalysts owing to the ambiguity in $\mathrm{CO}$ adsorption sites make detailed interpretation of the current densities in the 0.2 to $0.0 \mathrm{~V}$ range, corresponding to $\mathrm{H}_{\mathrm{abs}}$ and HER, inappropriate. However, it does appear that the onset for
HER is more positive for the Pd@Pt $\mathrm{P}_{0.5 \mathrm{ML}}$ catalyst compared to the $\mathrm{Pd} / \mathrm{C}$ catalyst, in agreement with Bartlett and Marwan's findings.

It is well established that Pt is a better HER catalyst than Pd and the onset potential for the HER is at more positive potentials for the $\mathrm{Pt} / \mathrm{C}$ reference catalyst as seen in Fig. $4 \mathrm{~b}$, in agreement with Trasatti's original measurements [46] and the DFT calculations of Norskov et al. [47] A study of the kinetics of $\mathrm{H}_{\mathrm{abs}}$ /hydride formation at the Pd@Pt catalyst electrodes using in situ time resolved EXAFS or XRD, such as those recently reported by Iwasawa's group for oxide formation at Pd@Pt catalysts [48] would be required to provide further comparison to this aspect of the thin film study by Bartlett and Marwan [45].

\section{Conclusions}

In summary, the effects of the thickness of the Pt shell on the electrochemical formation of the hydride phase for a series of Pd@Pt core-shell catalysts have been explored using in situ EXAFS and XRD measurements. The results show that formation of the $\beta$ phase is inhibited by the deposition of even $0.5 \mathrm{ML}$ of Pt onto the Pd core and at most a mixed $\alpha$ - and $\beta$-phase hydride is formed. The lattice expansion of $<0.6 \%$ observed, based on the in situ XRD measurements, was found for all of the core-shell catalysts. This is considerably less than the $3 \%$ increase observed for the Pd/C core at $0.0 \mathrm{~V}$. Thus, it is unlikely that hydride formation occurring during surface area measurements in the accelerated aging tests or caused by hydrogen cross-over will be a significant driving force in the degradation of Pd@Pt core-shell catalysts when used in a membrane electrode fuel cell compared to the effects of oxide formation previously explored in accelerated aging studies [20,21] and, more recently, in combined time resolved EXAFS and XRD studies [48].

\section{Acknowledgements}

The work was jointly supported by the EPSRC via the Doctoral Training Account and Johnson Matthey. The authors thank colleagues at the Johnson Matthey Technology Centre for their scientific input and assistance, including Sarah Ball, Brian Theobald, Elvis Christian, Beatrice Tessier, David Thompsett, Jonathan Sharman, and staff in the JMTC Analytical Department. Philip Bartlett, Guy Denuault, and John Owen, all of the Southampton Electrochemistry Group, are thanked for fruitful and lively discussions. Michelle Hamilton of the Research Complex at Harwell is thanked for completing the drawings of the cell shown in Fig. S2.

Beamtime allocated at the various synchrotron radiation sources is acknowledged as follows. X23A2 NSLS - Bruce Ravel. Use of the National Synchrotron Light Source, Brookhaven National Laboratory, was supported by the U.S. Department of Energy, Office of Science, Office of Basic Energy Sciences, under Contract No. DEAC02-98CH10886. BM26A ESRF - Sergey Nikitenko, Miguel Silveria and Wim Bras, and we acknowledge the European Synchrotron Radiation Facility for provision of synchrotron radiation facilities. X1 DORIS III at DESY- Adam Webb and Edmund Welter, and we thank the Helmholtz Association (HGF) for access to this source. B18 Diamond - Sylvia Ramos and we thank Diamond Light Source for access this source. 11-3, SSRL - Sumohan Misra. Provision of access to the Stanford Synchrotron Radiation Lightsource, a Directorate of SLAC National Accelerator Laboratory and an Office of Science User Facility operated for the U.S. Department of Energy Office of Science by Stanford University, is gratefully acknowledged. 


\section{References}

[1] H.A. Gasteiger, S.S. Kocha, B. Sompalli, F.T. Wagner, Activity benchmarks and requirements for Pt, Pt-alloy, and non-Pt oxygen reduction catalysts for PEMFCs, Appl. Catal. B Environ. 56 (2005) 9-35, https://doi.org/10.1016/ j.apcatb.2004.06.021.

[2] H.Y. Zhang, C.H. Cao, J. Zhao, R. Lin, J.X. Ma, Recent development of Pt-based core-shell structured electrocatalysts in fuel cells, Chin. J. Catal. 33 (2012) 222-229, https://doi.org/10.3724/sp.j.1088.2012.10947.

[3] J.B. Wu, H. Yang, Platinum-based oxygen reduction electrocatalysts, Accounts Chem. Res. 46 (2013) 1848-1857, https://doi.org/10.1021/ar300359w.

[4] M. Watanabe, D.A. Tryk, M. Wakisaka, H. Yano, H. Uchida, Overview of recent developments in oxygen reduction electrocatalysis, Electrochim. Acta 84 (2012) 187-201, https://doi.org/10.1016/j.electacta.2012.04.035.

[5] S.J. Guo, S. Zhang, S.H. Sun, Tuning nanoparticle catalysis for the oxygen reduction reaction, Angew. Chem. Int. Ed. 52 (2013) 8526-8544, https:// doi.org/10.1002/anie.201207186.

[6] J.L. Zhang, M.B. Vukmirovic, Y. Xu, M. Mavrikakis, R.R. Adzic, Controlling the catalytic activity of platinum-monolayer electrocatalysts for oxygen reduction with different substrates, Angew. Chem. Int. Ed. 44 (2005) 2132-2135, https://doi.org/10.1002/anie.200462335.

[7] J. Zhang, M.B. Vukmirovic, K. Sasaki, F. Uribe, R.R. Adzic, Platinum monolayer electro catalysts for oxygen reduction: effect of substrates, and long-term stability, J. Serb. Chem. Soc. 70 (2005) 513-525, https://doi.org/10.2298/ jsc0503513z.

[8] J. Zhang, Y. Mo, M.B. Vukmirovic, R. Klie, K. Sasaki, R.R. Adzic, Platinum monolayer electrocatalysts for O-2 reduction: Pt monolayer on $\mathrm{Pd}(111)$ and on carbon-supported Pd nanoparticles, J. Phys. Chem. B 108 (2004) 10955-10964, https://doi.org/10.1021/jp0379953.

[9] M.H. Shao, T. Huang, P. Liu, J. Zhang, K. Sasaki, M.B. Vukmirovic, R.R. Adzic, Palladium monolayer and palladium alloy electrocatalysts for oxygen reduction, Langmuir 22 (2006) 10409-10415, https://doi.org/10.1021/la0610553.

[10] A.U. Nilekar, Y. Xu, J.L. Zhang, M.B. Vukmirovic, K. Sasaki, R.R. Adzic, M. Mavrikakis, Bimetallic and ternary alloys for improved oxygen reduction catalysis, Top. Catal. 46 (2007) 276-284, https://doi.org/10.1007/s11244-0079001-z.

[11] N.V. Long, C.M. Thi, Y. Yong, M. Nogami, M. Ohtaki, Platinum and palladium nano-structured catalysts for polymer electrolyte fuel cells and direct methanol fuel cells, J. Nanosci. Nanotechnol. 13 (2013) 4799-4824, https://doi.org/ 10.1166/jnn.2013.7570.

[12] H. Zhang, M.S. Jin, Y.N. Xia, Enhancing the catalytic and electrocatalytic properties of Pt-based catalysts by forming bimetallic nanocrystals with Pd, Chem. Soc. Rev. 41 (2012) 8035-8049, https://doi.org/10.1039/c2cs35173k.

[13] K. Kusada, M. Yamauchi, H. Kobayashi, H. Kitagawa, Y. Kubota, Hydrogenstorage properties of solid-solution alloys of immiscible neighboring elements with Pd, J. Am. Chem. Soc. 132 (2010) 15896-15898, https://doi.org/10.1021/ ja107362z.

[14] H. Kobayashi, M. Yamauchi, H. Kitagawa, Y. Kubota, K. Kato, M. Takata, Atomic-level Pd-Pt alloying and largely enhanced hydrogen-storage capacity in bimetallic nanoparticles reconstructed from core/shell structure by a process of hydrogen absorption/desorption, J. Am. Chem. Soc. 132 (2010) 5576-5577, https://doi.org/10.1021/ja1013163.

[15] H. Kobayashi, M. Yamauchi, H. Kitagawa, Y. Kubota, K. Kato, M. Takata, Hydrogen absorption in the core/shell interface of Pd/Pt nanoparticles, J. Am. Chem. Soc. 130 (2008) 1818-1819, https://doi.org/10.1021/ja078126k.

[16] A.D. Lueking, R.T. Yang, Hydrogen spillover to enhance hydrogen storage study of the effect of carbon physicochemical properties, Appl. Catal. A Gen. 265 (2004) 259-268, https://doi.org/10.1016/j.apcata.2004.01.019.

[17] W.C. Conner, J.L. Falconer, Spillover in heterogeneous catalysis, Chem. Rev. 95 (1995) 759-788, https://doi.org/10.1021/cr00035a014.

[18] M. Yamauchi, H. Kobayashi, H. Kitagawa, Hydrogen storage mediated by Pd and Pt nanoparticles, ChemPhysChem 10 (2009) 2566-2576, https://doi.org/ 10.1002/cphc.200900289.

[19] E. Wicke, H. Brodowsky, H. Zuchner, Hydrogen in palladium and palladium alloys, in: Hydrogen in Metals II, vol. 29, Springer, Berlin, 1978, pp. 73-155, https://doi.org/10.1007/3-540-08883-0_19.

[20] DOE Cell Component Accelerated Stress Test Protocols for PEM Fuel Cells (http://energy.gov/sites/prod/files/2014/03/f10/component_durability_ profile.pdf).

[21] R. Petrone, D. Hissel, M.C. Péra, D. Chamagne, R. Gouriveau, Accelerated stress test procedures for PEM fuel cells under actual load constraints: state-of-art and proposals, Int. J. Hydrogen Energy 36 (2015) 12489-12505, https:// doi.org/10.1016/j.ijhydene.2015.07.026.

[22] S.C. Ball, Behaviour of core shell nanoparticle catalysts in the PEMFC environment, World J. Educ. 7 (2010) 87-88.

[23] A.E. Russell, B. Tessier, A. Wise, A. Rose, S.W.T. Price, P.W. Richardson, S. Ball, B. Theobald, D. Thompsett, E.M. Crabb, In situ XAS studies of core-shell PEM Fuel cell catalysts: the opportunities and challenges, ECS Trans. 41 (2011) 55-67.

[24] B.C. Tessier, A.E. Russell, B.R. Theobald, D. Thompsett, PtML/Pd/C core-shell electrocatalysts for the ORR in PEMFCs, ECS Trans. 16 (2009) 1-11, https:// doi.org/10.1149/1.3106718.

[25] E.M. Crabb, M.K. Ravikumar, Synthesis and characterisation of carbonsupported PtGe electrocatalysts for CO oxidation, Electrochim. Acta 46
(2001) 1033-1041, https://doi.org/10.1016/s0013-4686(00)00688-5.

26] E.M. Crabb, M.K. Ravikumar, Y. Qian, A.E. Russell, S. Maniguet, J. Yao, D. Thompsett, M. Hurford, S.C. Ball, Controlled modification of carbon supported platinum electrocatalysts by Mo, Electrochem. Solid State Lett. 5 (2002) A5-A9, https://doi.org/10.1149/1.1419703.

[27] P.P. Wells, E.M. Crabb, C.R. King, R. Wiltshire, B. Billsborrow, D. Thompsett, A.E. Russell, Preparation, structure, and stability of Pt and Pd monolayer modified Pd and Pt electrocatalysts, Phys. Chem. Chem. Phys. 11 (2009) 5773-5781, https://doi.org/10.1039/b823504j.

[28] B. Ravel, M. Newville, Athena Artemis, HEPHAESTUS: data analysis for X-ray absorption spectroscopy using IFEFFIT, J. Synchrotron Radiat. 12 (2005) 537-541, https://doi.org/10.1107/s0909049505012719.

[29] A.P. Hammersley, S.O. Svensson, M. Hanfland, A.N. Fitch, D. Hausermann, Two-dimensional detector software: from real detector to idealised image or two-theta scan, High Pres. Res. 14 (1996) 235-248, https://doi.org/10.1080/ 08957959608201408.

[30] F. Maillard, E.R. Savinova, U. Stimming, CO monolayer oxidation on Pt nanoparticles: further insights into the particle size effects, J. Electroanal. Chem. 599 (2007) 221-232, https://doi.org/10.1016/j.jelechem.2006.02.024.

[31] P. Canton, G. Fagherazzi, M. Battagliarin, F. Menegazzo, F. Pinna, N. Pernicone $\mathrm{Pd} / \mathrm{CO}$ average chemisorption stoichiometry in highly dispersed supported $\mathrm{Pd} / \gamma-\mathrm{Al}_{2} \mathrm{O}_{3}$ catalysts, Langmuir 18 (2002) 6530-6535, https://doi.org/ 10.1021/la015650a.

[32] A.E. Russell, A. Rose, X-ray absorption spectroscopy of low temperature fue cell catalysts, Chem. Rev. 104 (2004) 4613-4636, https://doi.org/10.1021/ cr020708r.

[33] R.J. Davis, S.M. Landry, J.A. Horsley, M. Boudart, X-ray absorption study of the interaction of hydrogen with clusters of supported palladium, Phys. Rev. B 39 (1989) 10580-10583, https://doi.org/10.1103/PhysRevB.39.10580.

[34] J.A. McCaulley, In-situ X-ray absorption spectroscopy studies of hydride and carbide formation in supported palladium catalysts, J. Phys. Chem. 97 (1993) 10372-10379, https://doi.org/10.1021/j100142a018.

[35] A. Rose, S. Maniguet, R.J. Mathew, C. Slater, J. Yao, A.E. Russell, Hydride phase formation in carbon supported palladium nanoparticle electrodes investigated using in situ EXAFS and XRD, Phys. Chem. Chem. Phys. 5 (2003) 3220-3225, https://doi.org/10.1039/b302956e.

[36] W. Vogel, W. He, Q.H. Huang, Z.Q. Zou, X.G. Zhang, H. Yang, Palladium nanoparticles "breathe" hydrogen; a surgical view with X-ray diffraction, Int J. Hydrogen Energy 35 (2010) 8609-8620, https://doi.org/10.1016/ j.ijhydene.2010.05.117.

[37] L. Liu, G. Samjeske, S.I. Nagamatsu, O. Sekizawa, K. Nagasawa, S. Takao, Y. Imaizumi, T. Yamamoto, T. Uruga, Y. Iwasawa, Enhanced oxygen reduction reaction activity and characterization of $\mathrm{Pt}-\mathrm{Pd} / \mathrm{C}$ bimetallic fuel cell catalysts with Pt-Enriched surfaces in acid media, J. Phys. Chem. C 116 (2012) 23453-23464, https://doi.org/10.1021/jp308021a.

[38] B. Ingham, M.F. Toney, S.C. Hendy, T. Cox, D.D. Fong, J.A. Eastman, P.H. Fuoss, K.J. Stevens, A. Lassesson, S.A. Brown, M.P. Ryan, Particle size effect of hydrogen-induced lattice expansion of palladium nanoclusters, Phys. Rev. B 5 (2008) 78, https://doi.org/10.1103/PhysRevB.78.245408.

[39] G. Jerkiewicz, Hydrogen sorption at/in electrodes, Prog. Surf. Sci. 57 (1998) 137-186, https://doi.org/10.1016/S0079-6816(98)00015-X.

[40] B.E. Conway, G. Jerkiewicz, Thermodynamic and electrode kinetic factors in cathodic hydrogen sorption into metals and its relationship to hydrogen adsorption and poisoning, J. Electroanal. Chem. 357 (1993) 47-66, https:// doi.org/10.1016/0022-0728(93)80373-P.

[41] B.E. Conway, G. Jerkiewicz, Factors in the electrolytic sorption of $\mathrm{H}$ into metals and its relation to hydrogen evolution kinetics, Zeit. Phys. Chem. Bd. 183 (1994) 281-286 doi not available.

[42] M. Grden, A. Piascik, Z. Koczorowski, A. Czerwinski, Hydrogen electrosorption in Pd-Pt alloys, J. Electroanal. Chem. 532 (2002) 35-42, https://doi.org/ 10.1016/S0022-0728(02)00750-7.

[43] S. Kandoi, P.A. Ferrin, M. Mavrikakis, Hydrogen on and in selected overlayer near-surface alloys and the effect of subsurface hydrogen on the reactivity of alloy surfaces, Top. Catal. 53 (2010) 384-392, https://doi.org/10.1007/s11244010-9444-5.

[44] P.N. Bartlett, J. Marwan, The effect of surface species on the rate of $\mathrm{H}$ sorption into nanostructured Pd, Phys. Chem. Chem. Phys. 6 (2004) 2895-2898, https://doi.org/10.1039/b404028g.

[45] S. Trasatti, Work function, electronegativity, and electrochemical behaviour of metals III: electrolytic hydrogen evolution in acid solutions, J. Electroanal. Chem. 39 (1972) 163-184, https://doi.org/10.1016/0368-1874(72)85118-9.

[46] J.K. Norskov, T. Bligaard, A. Logadottir, J.R. Kitchin, J.G. Chen, S. Pandelov, Trends in the exchange current for hydrogen evolution, J. Electrochem. Soc. 152 (2005) J23-J26, https://doi.org/10.1149/1.1856988.

[47] S.-I. Nagamatsu, S. Takao, G. Samjeske, K. Nagasawa, O. Sekizawa, T. Kaneko, K. Higashi, T. Uruga, S. Gayen, S. Velaga, M.K. Saniyal, Y. Iawsawa, Structural and electronic transformations of Pt/C, Pd@Pt(1 ML)/C and Pd@Pt(2 ML)/C cathode catalysts in polymer electrolyte fuel cells during potential-step operating processes characterized by in-situ time-resolved XAFS, Surf. Sci. 648 (2016) 100-113, https://doi.org/10.1016/j.susc.2015.10.053.

[48] O. Sekizawa, T. Uruga, K. Higashi, T. Kaneko, Y. Yoshida, T. Sakata, Y. Iwasawa, Simultaneous operando time-resolved XAFS-XRD measurements of a Pt/C cathode catalyst in polymer electrolyte fuel cell under transient potential operations, ACS Sustain. Chem. Eng. 5 (2017) 3631-3636. 